\title{
Impact of biomass burnings in South East Asia on air quality and pollutants transport during the end of the 2019 dry season
}

Hiep Nguyen Duc ( $\nabla$ nguyenduchiep@tdtu.edu.vn )

Environment Quality, Atmospheric Science and Climate Change Research Group, Ton Duc Thang University, Ho Chi Minh, Vietnam https://orcid.org/0000-0002-6658-4382

Ho Quoc Bang

Institute for Environment and Resources, Vietnam National University, Ho Chi Minh City, Vietnam

Nguyen Hong Quan

Center for Water Management and Climate Change, Vietnam National University, Ho Chi Minh City 700000, Vietnam

\section{Ngo Xuan Quang}

Department of Environmental Management and Technology, Institute of Tropical Biology, Vietnam Academy of Science and Technology, Ho Chi Minh City, Vietnam

\section{Research Article}

Keywords: Biomass burnings, South East Asia, WRF-Chem, FINN, air quality model, population exposure

Posted Date: June 22nd, 2021

DOl: https://doi.org/10.21203/rs.3.rs-643754/v1

License: (9) This work is licensed under a Creative Commons Attribution 4.0 International License. Read Full License 


\section{Abstract}

At the end of the dry season, March and April in South East Asia (SEA), agricultural refuse burnings occur over the region, mainly in the countries of Myanmar, Thailand, Laos, Cambodia and Vietnam, in preparation for the wet rice plantation. In this study, the impact of biomass burnings at the height of the burning period in March 2019 in mainland SEA on air quality and pollutant transport is modelled using the Weather Research Forecast WRF-Chem air quality model with emission input from the National Center for Atmospheric Research (NCAR) Fire Emission Inventory from NCAR (FINN). FINN is derived from satellite remote sensing data and species emission factors. A simulation of the dispersion of pollutants from biomass burnings from 13 to 19 March 2019, when the burnings was most intense, was performed. Validation of the model prediction using observed meteorological and pollutants data such as AOD measurements on ground from AERONET (Aerosol Robotic Network) and data from MODIS and CALIPSO satellites are carried out at various sites in the region.

The results show that impact on air quality was most pronounced in Thailand and Laos but the effect of biomass burnings in mainland SEA at the end of the dry season is widespread in terms of pollutant dispersion and population exposure over the whole region and beyond. It is also shown that the transport of pollutants from biomass burnings in SEA to southern China, Taiwan and beyond is facilitated by the Truong Son mountain range, when under westerly wind, acting as a launching pad to uplift the pollutant plumes to higher altitude which then can be dispersed widely and transported farther from the biomass burning sources in Thailand and Laos.

\section{Introduction}

Biomass burnings of agricultural waste before the start of monsoon in South East Asia (SEA) emit large amount of gaseous pollutants and aerosols which can cause elevated concentrations in South East Asia and beyond. One of the pollutants of concerns is black carbon (BC), a marker for smoke, is a component of aerosol particles of various sizes and is harmful to health. Smoke from hazard reductions and wildfires creates health hazards for communities exposed to smoke, particularly to people with existing conditions such as cardiovascular, respiratory, and asthmatic (Marlier et al. 2012, Salimi et al. 2017, Broome et al. 2016). Seasonally, there are two particular patterns of biomass burnings in SEA, mainland SEA in March-April and maritime SEA in September-October when smoke plumes from fires cover much of the region. Mainland SEA, consisting of the country areas of Myanmar, Thailand, Laos, Cambodia and Vietnam, has widespread agricultural biomass burnings at the end of the dry season mostly during March and April. While maritime SEA (Indonesia, Malaysia, Singapore) has smoke haze covering the region from intense fires (agricultural biomass burnings and peat fires) mostly in Sumatra and Kalimantan of Indonesia, south of the equator during the dry season and in August to October (Field et al. 2016).

Remote sensing data from satellites are gradually available for research with rich data sets released on global and local scale allow researchers to study the emission and dispersion pattern of particles such as black carbon in South East Asia (SEA) from biomass burnings and anthropogenic combustion sources. 
Long range transport of particles from dust storm or biomass burnings have been shown to occur in many parts of the world including SEA (Deng et al. 2008, Lin et al., 2014, Vadrevu et al., 2014, Chang et al. 2015, Kong et al., 2018, Duc et al. 2018, Thanh et al., 2019). Recently Kong et al. 2018, using CMAQ (Community Multiscale Air Quality Model System) air quality model with windblown dust module, have shown that dust storm events in East Asia deserts such as the Taklamakan and Gobi deserts can travel to Taiwan during the spring season. Large scale biomass burnings during the end of the dry season in South East Asia and Indian sub-continent have been shown to affect air quality not only in the source regions but also in Hong Kong, Taiwan and Southern China (Duc et al. 2016, Huang et al. 2013). In particular, Huang and Lin (2015) have shown that the biomass burnings in peninsular Indochina in March and April affect the fine aerosols concentration and AOD in South China Sea (SCS) and SEA as detected and measured by AERONET network sites at Dongsha island, Bac Lieu, Hong Kong, Pimai, Singapore and Mukdahan and by MODIS satellites. For coarse mode aerosols, mostly from dust and marine aerosols, China was a significant source of this type of aerosols.

Lin et al. (2014) used WRF-Chem to simulate the effects of biomass-burnings Indochinese peninsula on transported aerosols and other pollutants to Taiwan during the study period of 15-18 March 2008 and compared the simulated AOD with observed AOD from AERONET ground network and satellite data. The predicted AOD corresponds well with the observed data. The WRF-Chem model was proved to be useful in studying the dispersion and transport of emitted pollutants from fires as they have shown. Aouizerats et al. 2015 also used WRF-Chem model based on volatility basis set (VBS) scheme for both primary and secondary aerosols to show the transboundary air pollution from Indonesia to Singapore from large fire events in 2006. The Global Fire Emission Database (GFED3) was used in their WRF-Chem model simulation and AOD data from four different sensors including one from MODIS were used to compare with the model output. Xing et al. 2020 studied the contribution of sources (anthropogenic and biomass burnings) to 2017 Elemental Carbon (EC) annual concentration in Thailand. In their WRF-Chem study, the modelling domain enclosed sources in Thailand and outside Thailand and practically cover most of SEA. Other air quality model which was used in the study of impact assessment of biomass burnings in SEA is WRF-CMAQ (Huang et al. 2013, Takami et al. 2020). Vadrevu et al. 2014 however, instead of using modelling method, only used long record of remote sensing data to show that biomass burnings for land clearing as opposed to agricultural waste burnings in June 2013 in Indonesia (Riau Province) had caused high pollution episode as measured by AOD and aerosols from smoke plumes were transported to northward to Singapore, Malaysia and southern Thailand.

Dispersed particle concentration pattern from biomass burnings in mainland SEA over the region in general and in particular over Vietnam is dependent on the location of the fires each year and the meteorological condition during the fire period. But a distinct pattern emerges and shows biomass burnings in Myanmar, Thailand and Cambodia affect ambient aerosols and BC concentration over Vietnam, southern China, Taiwan and the East Sea (South China Sea) annually in March and April by the dispersion and transport of pollutants under westerly and south-westerly wind flow. During this time, SEA was at the end of the dry season. To simulate the dispersion and concentration of pollutants within SEA and beyond from biomass burnings, an air quality model is usually used. This study used WRF-Chem for 
this purpose focusing on the 2019 dry season period. Figure 1 shows the monthly rainfall for March and April 2019 as measured by Tropical Rainfall Measuring Mission (TRMM) satellite and provided as an 3B43 product of TPMA (TRMM Multi-satellite Precipitation Analysis). The satellite record shows that there was little or no rainfall across mainland South East Asia during this period compared to maritime SEA and southern China.

Two sources of remote sensing data that are useful for assessment the scale and effect of biomass burnings are the MODIS Terra/Aqua and CALIPSO lidar products. Intense biomass burnings across South East Asia during March 2019 period were detected by MODIS Aqua/Terra satellites. Figure 2 shows the hot spots of fires and AOD over South East Asia as detected from MODIS satellites. Vertical profiles of aerosol from lidar CALIOP onboard CALIPSO satellite revealed the fine structure of aerosols with different aerosol types. The lidar of aerosols profile allows one to determine the height of the smoke aerosols above ground and is most useful as it can distinguish between smoke aerosol from other types of aerosols such as marine aerosols, volcanic ashes, sulfate aerosols and dust. All of these types of aerosol contribute to the overall AOD.

To understand how the emitted pollutants such as $\mathrm{PM}_{2.5}$ dispersed from biomass burnings across a large region, it is important to determine the sources of emission, how much and how long the emission occurred and how these pollutants were dispersed and transported from the burning sites to receptors within and outside the peninsular SEA. To overcome these difficulties and challenges, we use the fire emission inventory based on hot spots location detected by satellite, on emission estimates from the hot spots for each of the emitted species and an air quality model (WRF-Chem) which allowed us to determine the dispersion and concentration of aerosols $\left(\mathrm{PM}_{2.5}\right)$ in much more detailed at all grid points in the SEA domain. Modelling also allows us to understand the vertical aerosol distribution and the wind patterns at different level heights and hence allows one to determine the transport mechanism from SEA to East Asia. In this study, the dispersion pattern of air pollutants emitted from biomass burnings and their effect on air quality are studied in detail during 13 to 19 March 2019 period. We use observation data from various sources and model simulation to study the transport of air pollutants, such as $\mathrm{PM}_{2.5}$ and black carbon (BC) from biomass burnings, particularly during the period of March 2019 in peninsular mainland SEA. The characteristics of spatial and temporal patterns of $\mathrm{PM}_{2.5}$ and black carbon (BC) dispersion over SEA will be analysed and determined with focus on Thailand, Laos and Vietnam using these data sources as well as using WRF-Chem air quality model. The WRF-Chem model has been used by many authors to study air quality impact from biomass burnings in SEA such as Lin et al. 2014, Xing et al. 2020, Aouizerats et al. 2015.

To be able to use the air quality model, the emission data from the fires has to be quantified or accounted for. Currently the two most used fire emission data are GFED and FINN. FINN provides high temporal (daily) and spatial emission ( $1 \mathrm{~km}$ resolution) in near real-time and can be used for photochemical air pollution forecasting while the current version GFED- 4 is at $0.25^{\circ}$ by $0.25^{\circ}$ resolution on the global scale and provides monthly emission data (Randerson et al. 2018). Both GFED and FINN are based on MODIS 
satellite to estimate the burn areas and the emission factors from Andreae and Merlet scheme (Andreae, Merlet 2001). However, the fuel load estimate by GFED is based on CASA (Carnegie Ames Stanford Approach) modelling framework using NPP (Net Primary Production) as a surrogate for fuel load while FINN uses MODIS satellite data for fuel load.

Our objective is to quantify the impact of biomass burnings at the height of the burning period in March 2019 in mainland SEA on air quality and to understand the mechanism for the pollutant long-range transport from SEA to East Asia (Taiwan, Southern China). In our study, the WRF-Chem model is used with FINN (Fire Emission Inventory from NCAR) and the anthropogenic global emission inventory from EDGAR-HTAP (Emission Database for Global Atmospheric Research - Hemispheric Transport of Air Pollution) with $0.1^{\circ} \times 0.1^{\circ}$ resolution as model input to predict the distribution of aerosols including $\mathrm{PM}_{2.5}$ and BC across South East Asia and Vietnam. The chemistry mechanism used in our study is MOZART/GOCART (Model of Ozone and Related Chemical Tracers/ Goddard Chemistry Aerosol Radiation and Transport) as FINN emission of chemical species are available for this chemical mechanism (Wiedinmyeret al., 2010).

The prediction of AOD, during a period of burnings from the WRF-Chem air quality model and from NASA MERRA-2 model (Modern-Era Retrospective analysis for Research and Applications) data is compared with AOD observation from AERNONET and from ground-based data to validate the models. To evaluate WRF-Chem performance in their study of pollutants transport from biomass burnings in SEA to Taiwan during 9 to 18 March 2008, Lin et al (2014) compare the predicted daily average of AOD and observed daily average AOD at a number of sites where AERONET data are available. In our study, this approach is also adopted to evaluate the WRF-Chem model performance in addition to using CALIPSO vertical profile.

\section{Data And Method}

Data used this study include AERONET (Aerosol Robotic Network) data from various sites in the AERONET network (aeronet.gsfc.nasa.gov) and CALIOP vertical lidar profile from CALIPSO satellite. The data cover the period from 10 March 2019 to 19 March 2019 when the highest columnar aerosol AOD values were detected at AERONET sites in peninsular Indochina due to biomass burnings location in Burma, Thailand, Cambodia, Laos and Vietnam. The WRF-Chem model is used to simulate the formation and dispersion and transport of particles from biomass fire sources during 10 to 19 March 2019. As mentioned above, this requires the emission data input which is obtained from FINN emission database. The FINN (Fire Emission Inventory from NCAR) emission database contains fire emission data at $1 \mathrm{~km}$ resolution derived from MODIS Rapid Response fire count (Fire Information for Resource Management System, FIRMS) hot spots (Wiedinmyer et al. 2014). These data are usually provided on the daily basis at hourly resolution (archived into yearly or monthly data) and can be downloaded and then converted into WRF emission input files. The "base" fire emission datasets are available for 3 chemical mechanisms, GEOS-CHEM, MOZART-4 ("MOZ4") and SAPRC99. An example of emission for BC and $\mathrm{PM}_{2.5}$ as provided 
by FINN is shown in Figure 3 on 14/3/2019 at 16:00 UTC. The spatial pattern of emission corresponds to the hot spots as detected by MODIS.

A Fortran program (fire_emis) was used to convert these fire emission datasets into emission input to WRF-Chem. The modelling domain contains nearly all the fire emission sources as detected by satellites as hot spots and anthropogenic emission sources using EDGAR-HTAP global emission data set. Figure 4 shows the modelling domain for WRF-Chem simulation in this study.

As for meteorological driver, the National Centre for Environmental Prediction (NCEP) Final Analysis (FNL) Reanalysis data provides the boundary and initial meteorological condition for WRF-Chem model to downscale the meteorological field to the study modelling domain at the specified resolution.

To evaluate the performance of WRF-Chem, the predicted AOD at 550nm wavelength will be compared with the observed AOD data as measured from AERONET sites. The predicted AOD is calculated from the predicted extinction coefficients at 550nm as an output variable of WRF-Chẹm

\section{See formula 1 in the supplementary files section.}

The global modelled and reanalysis dataset at lower resolution from MERRA-2 is used to corroborate with the results. Observed meteorological data from automatic weather stations on ground will also be used to verify the meteorological prediction.

\section{Anthropogenic and biogenic emission data and WRF-Chem configuration}

The chemical mechanism selected for this study is MOZART (Model of Ozone and Related Chemical Tracers) for gas phase chemistry and GOCART (Goddard Chemistry Aerosol Radiation and Transport) for aerosol phase (chem_opt=112 in namelist.input of WRF-Chem). The MOZART/GOCART (MOZCART) is chosen as the fire emission data used in the study is FINN, which currently provides daily emission data at $1 \mathrm{~km}$ resolution for 3 chemical model GEO-Chem, MOZART and SAPRC99. The NCAR anthro_emis program is used to prepare the anthropogenic emission data for the simulation domain using the global annual emission EDGAR-HTAP at $0.1^{\circ} \times 0.1^{\circ}$ resolution suitable for MOZCART mechanism (JanssensMaenhout et al. 2015, Crippa et al. 2020). The boundary and initial condition were generated from mozbc program using chemical profile from global MOZART model output which is available from https://www.acom.ucar.edu/waccm/download.shtml.

For biogenic emission, we use the inline Model of Emissions of Gases and Aerosols from Nature (MEGAN) biogenic emission within WRF-Chem. Option bio_emiss_opt $=3$ is therefore chosen for inline biogenic emission based on MEGAN scheme.

The domain is defined as $354 \times 315$ gridded lat-lon projection with resolution $0.0577^{\circ} \times 0.0576^{\circ}$ (or $6418 \mathrm{~m} \times 6410 \mathrm{~m}$ ) and 32 model vertical sigma levels with top of the domain at pressure $5000 \mathrm{~Pa}$. The centre reference coordinate is $104.594^{\circ}$ longitude and $16.274^{\circ}$ latitude. 
Table 1 shows some of the WRF-Chem physics and chemistry configuration options used in this study

\begin{tabular}{|c|c|c|c|}
\hline Physical parametrisation & Namelist variable & Option & Model/scheme \\
\hline Microphysics & mp_physics & 3 & WRF Single Moment \\
\hline Land surface & sf_surface_physics & 2 & Noah Land-Surface Model \\
\hline Surface layer physics & sf_sfclay_physics & 1 & Monin-Obukhov similarity \\
\hline Planetary Boundary Layer & bl_pbl_physics & 1 & YSU scheme \\
\hline Shortwave radiation & ra_sw_physics & 4 & $\begin{array}{l}\text { Rapid Radiative Transfer Model } \\
\text { (RRTMG) }\end{array}$ \\
\hline Long wave radiation & ra_Iw_physics= & 4 & $\begin{array}{l}\text { Rapid Radiative Transfer Model } \\
\text { (RRTMG) }\end{array}$ \\
\hline Cumulus cloud & cu_physics & 1 & Kain-Fritsch scheme \\
\hline Gas/aerosol Chemistry & chem_opt & 112 & MOZART/GOCART \\
\hline Biomass burning option & biomass_burn_opt & 2 & $\begin{array}{l}\text { Emission and plume rise for } \\
\text { MOZCART }\end{array}$ \\
\hline Sea salt emission & seas_opt & 1 & $\begin{array}{l}\text { GOCART sea salt emission } \\
\text { scheme }\end{array}$ \\
\hline Photolysis & phot_opt & 3 & Madronich F-TUV photolysis \\
\hline Dust scheme & dust_opt & 3 & GOCART-AFWA scheme \\
\hline $\begin{array}{l}\text { Aerosol extinction coefficient } \\
\text { approximation }\end{array}$ & aer_opt_opt & 2 & Maxwell-Garnett approximation \\
\hline Aerosol radiative feedback & aer_ra_feedback & 1 & $\begin{array}{l}\text { Turn on aerosol radiative } \\
\text { feedback with RRTMG model }\end{array}$ \\
\hline
\end{tabular}

Table 1 - WRF-Chem configuration in the namelist.input

As indirect effect of aerosols on cloud physics and radiation is not considered as in climate study or WRF-Chem two-way interaction, the microphysics scheme used in this study is the WRF Single-Moment (WSM) 3-class suitable for mesoscale grid sizes (mp_physics=3). Similar to Fountoukis et al., 2016 study, the surface layer physics is based on the Monin-Obukhov similarity scheme (sf_sfclay_physics=1), which is compatible with the planetary boundary layer (PBL) YSU (Yonsei University) model. And the land surface model used is the Noah Land-Surface Model which are used in Cavazos-Guerra and Todd 2012, Zhao et al., 2011 studies. This configuration was similar to that used in our previous WRF-Chem simulation study on the dispersion and transport of dust and aerosols from wildfires from Australia to New Zealand and Antarctica (Nguyen et al. 2019b) in which the meteorological and aerosol concentration prediction were comparable with observed ground and remote sensing data. 


\section{Results}

The simulation was conducted for the period from 13/3/2019 to 19/03/2019 inclusively, when the biomass burnings caused extensive smoke clouds with high AOD across South East Asia. As predicted from WRF-Chem, meteorological condition on mainland South East Asia in the modelling domain showed the prevailing surface wind changed from northernly on 13/3/2019 to north-easterly and easterly from southern China and the East Sea (South China Sea) during the period from 13/3/2019 15:00 UTC to 15/3/2019 12:00 UTC. After 15/3/201912:00 UTC, the northernly flow in dominant again. As shown in Figure 5, this wind pattern facilitated the transport of pollutants emitted from biomass burnings in Indochina to Thailand and the Gulf of Thailand, and from Thailand to Myanmar and to the Andaman Sea.

The prevailing surface wind is northernly and north-easterly from 13 to 17 March 2019, the ground $\mathrm{PM}_{2.5}$ concentration from the biomass burnings in northern Thailand and Laos mostly affected only Thailand and Laos. The biomass burnings in those areas did not affect Vietnam. Even when the wind was westerly in Cambodia and southern Vietnam on 18 and 19 March 2019, biomass burnings in northern Cambodia did not affect ground concentration of $\mathrm{PM}_{2.5}$ in Vietnam. The tailing end of the Truong Son mountain range, Central Highlands of Vietnam, effectively prevents advective wind transport of emitted pollutants at ground level but lifted pollutants to higher levels above ground on the other side of the Highlands near the coast.

Meteorological data from surface stations obtained from NOAA Integrated Surface Data (ISD) of world stations are used to compare with WRF-Chem prediction. Figure 6 shows the predicted temperature, wind speed and wind direction compared with corresponding observed values at Luang Namtha (northern Laos) and Bangkok International Airport (central Thailand) during 13 to 19 March 2019. The meteorological prediction, in general, corresponds well with observation except for the over prediction of wind speed at Luang Namtha. This can also be due to a significant number of missing hourly values for observed wind speed and wind direction at Luang Namtha.

The predicted daily average $\mathrm{PM}_{2.5}$ concentration for the simulated days of 13 to 18 March 2019 are shown in Figure 7. $\mathrm{PM}_{2.5}$ concentration mostly occurred in northern Laos, north and north-eastern Thailand where the biomass burnings were most intense, as indicated by the number of detected hot spots by MODIS in those regions. As the prevailing surface wind was north-easterly and easterly, the extend of the smoke plume was expanding mostly to the west and south of Thailand as shown in Figure 7 on 15 to 17 of March 2019 from the area of high $\mathrm{PM}_{2.5}$ concentration of smoke particle in Laos, northern Thailand and northern Cambodia near the border with Vietnam's Central Highlands. This corresponds to the location of hot spots as detected by MODIS satellite as shown in Figure 2.

The predicted concentration of $\mathrm{PM}_{2.5}$ in the gridded modelling domain can be useful for epidemiological study by allowing one to estimate population exposure and health impact of particulate $\mathrm{PM}_{2.5}$ concentration with respect to some health endpoints (mortality, respiratory and cardiac diseases hospital 
admission). , The wind patterns at upper atmospheric levels are different from those on the ground and cause the dispersion of the smoke clouds more widely compared to the transport of particles on the surface. At height level of about $1570 \mathrm{~m}$, the $\mathrm{PM}_{2.5}$ concentration is dispersed widely, and extend to the east of Laos crossing the Truong Son mountain range running from northernly Laos along the border with Vietnam to the Central Highlands. Figure A.2 in the Appendix shows the predicted $\mathrm{PM}_{2.5}$ and wind pattern on 16/3/2019 12:00 UTC at heights $900 \mathrm{hPa}(\sim 1000 \mathrm{~m}), 850 \mathrm{hPa}(\sim 1500 \mathrm{~m}), 700 \mathrm{hPa}(\sim 3000 \mathrm{~m})$ and $600 \mathrm{hPa}(\sim 3500 \mathrm{~m})$. The white areas on top and along the Truong Son range in the first 2 graphs indicate the mountain heights at those positions are higher than the heights of constant pressure at $900 \mathrm{hPa}$ and $850 \mathrm{hPa}$.

The time evolution of the predicted $\mathrm{PM}_{2.5}$ layers at various heights helps us to understand the dispersion and transport of air pollutants during the simulation period. This can also be summarised using the daily average of $\mathrm{PM}_{2.5}$ at a particular height. Figure 8 shows the daily average concentration of $\mathrm{PM}_{2.5}$ at height 1570m for the period 13 to 18 of March 2019. Comparison of these patterns daily average concentration in Figure 8 with those on the ground in Figure 5 shows the more extensive dispersion of $\mathrm{PM}_{2.5}$ smoke aerosols high above ground in the atmosphere and the shifted location of the high daily concentration of $\mathrm{PM}_{2.5}$ due to difference in wind conditions at the high altitude and on the ground. AOD as measured by ground based AERONET sites or by satellites takes into account all layers of aerosols in the column of the atmosphere. For this reason, a comparison of the predicted AOD and observed AOD is necessary and is considered next to evaluate the performance of the WRF-Chem model and to understand the dynamics of aerosol transport in this study.

Evaluation of WRF-Chem simulation

The daily spatial pattern of $\mathrm{PM}_{2.5}$ at level $\sim 1570 \mathrm{~m}$ corresponds more closely to the columnar AOD MODIS data as shown in Figure 2 as compared to the predicted ground concentration of $\mathrm{PM}_{2.5}$. For temporal domain, a comparison of predicted AOD hourly time series from 13 to 19 March 2019 of the simulation period at a number of locations in the domain with observed time series data from AERONET sites is conducted to validate the WRF-Chem model prediction. The quality of observed AOD is varied depending on the sites. Missing data frequently occur at most sites at various wavelengths. The predicted AOD from WRF-Chem is simulated and calculated for $550 \mathrm{~nm}$ wavelength via the extinct coefficient at this wavelength. However, the AERONET sites measure columnar AOD at many different wavelengths but rarely have available data at this wavelength. We use the closest observed AOD wavelength to the predicted 550nm AOD wavelength to compare the predicted and observed time series of AOD. The higher the wavelength, the less attenuation of lidar by aerosols.

Figure 9 shows the predicted AOD hourly time series and observed AERONET data series (level 2 data, time interval varying from 3 minutes to 15 minutes) at 8 AERONET sites, Chiang Mai meteorological station, Fang in northern Thailand, Luang Namtha in northern Laos, Nong Khai, Ubon Ratchathani in northeast Thailand, Bangkok in central Thailand, Bac Liêu and Nha Trang in southern Vietnam for the simulation period of 13 to 19 March 2019. There was no AERONET stations in northern Vietnam and in 
Cambodia that have available data for the study period. Even though the wavelength used to determine the predicted AOD is different from those of measurements at AERONET sites, the trends of observed data correspond with those of the predicted AOD time series at the sites. Lin et al. 2014 interpolated the observed AOD measured at wavelength $675 \mathrm{~nm}$ and at $440 \mathrm{~nm}$ to obtain the AOD at $550 \mathrm{~nm}$ so that a comparison can be made with predicted AOD at 550nm.

Lin et al. 2014 reported that their simulated AOD, using WRF-Chem for 11 to 19 March 2008, reached as high as $0.8-1.2$ in Indochina situated between $10-22^{\circ} \mathrm{N}$ and $95-107^{\circ} \mathrm{E}$. This corresponds to our results for Chiangmai, Fang, Luang Namtha, Bangkok, Ubon Ratchathani, Nong Khai where the biomass burnings were most intense and fall within the specified location range above. Our results for simulated AOD at 550nm wavelength on 13 to 19 March 2019 for those sites have values reaching higher than 1.5 and up to 2 at some particular time. The simulated AOD values for the two sites in coastal Vietnam, Nha Trang and Bac Lieu which are outside the specified location range, are lower at values below 0.5. These values, when compared to observed $A O D$ values at $500 \mathrm{~nm}$ wavelength varying below maximum value of about 1, are underpredicted. Lin et al. 2014 study also reported the predicted daily average of AOD at Bac Lieu as less than 0.4 during the 9 to 18 March 2008 period. The underpredicted AOD values at these sites, further from the main biomass burnings sources in Thailand and Laos, can be due to uncertainties in emission and meteorological data in addition to the local emission sources of fires not accounted for in the FINN emission data derived from MODIS detected hot spots.

Data from AERONET network at a number of sites in Central and Southern Vietnam, such as Nha Trang, Bac Lieu in February and March 2019 for all wavelengths as shown in Figure 10, show that peak values at Nha Trang (Central Vietnam) occurred in late February (22 to 25 February 2019) and mid-March (10 to 15 March 2019) and at Bac Lieu in early February (2 to 4 February 2019) and mid-March (12 to 17 March 2019).

The AOD as measured by MODIS Terra/Aqua satellites during mid-March 2019 also show thick aerosol layers above South East Asia peninsular, especially over Indochina. Figure A.1 of Appendix 1 shows MODIS Terra/Aqua AOD from 12 to 19 March 2019. It is clear from Figure 10 that the AOD time series at Nha Trang and Bac Lieu have peak values in March and occurred from 10 to 18 March for Nha Trang and 15 to 18 March for Bac Lieu. These high values corresponded to the spatial distribution of AOD over Central and Southern Vietnam as shown in Figure A.1 of the Appendix. Smoke aerosols are detected in all the profiles above the location corresponding to the sources as well as above the East Sea off the coast between Vietnam and the Philippines. The predicted AOD on 14 March 2019 at 00:00 UTC from WRFChem simulation during the period of 10 to 19 March 2019 is shown in Figure 11. The AOD pattern for this time corresponds to overall pattern for the day as in Figure A.1 (c).

The predicted AOD from our WRF-Chem model can also be compared with Total Aerosol Extinction AOT [550 nm] as predicted from MERRA-2 global reanalysis aerosol datasets for the sites in Thailand. They are similar in magnitude and trend but there is some difference in the detailed hourly fluctuation as Figure 12 shows for the two sites in northern Thailand (Chiang Mai) and Laos (Luang Namtha) as an example. 
This is expected as MERRA-2 is based on GEOS- 5 global model with $0.5^{\circ} \times 0.66^{\circ}$ grid resolution and assimilates meteorological and space-based observation to produce reanalysis aerosol datasets for long term analysis while WRF-Chem used in our study was not run with assimilation of observed data but has higher spatial resolution.

Vertical profile of smoke aerosols from lidar on CALIPSO satellite is used to assess the WRF-Chem prediction of aerosol dispersion. Contrary to AOD from MODIS/Aqua-Terra satellites which provides a view from above twice daily in an area, vertical profile of aerosols from CALIPSO satellite lidar provides a snapshot of aerosols vertically over its paths. The satellite path usually passes over South East Asia (SEA) a few days apart. During the simulation period from 13 to 19 March 2019, the smoke layers between above ground level up to $5 \mathrm{~km}$-high level as detected by CALIOP lidar onboard CALIPSO satellite and are shown in Figure 13 (smoke aerosols as black colour in the profile).

From Figures 2 and 13, it is clear that the fire hot spots and AOD patterns, formed from particle generated by fires as detected by MODIS satellites, from above ground on the 12, 15, 16 of March and 17 April 2019 correspond with the vertical profiles of particles along the CALIPSO satellite paths. The CALIPSO path on 12/03/2019 between 6:40 to 6:54 UTC, as shown in Figure 13(a), shows smoke aerosol layers above the Gulf of Thailand and central Thailand between $\left(9.11^{\circ}\right.$ lat, $105.02^{\circ}$ lon $)$ and $\left(18.25^{\circ}\right.$ lat, $103^{\circ}$ lon $)$. Figure 13 (b) shows thicker and more extensive smoke layers of 2.5 to $5 \mathrm{~km}$ high on 15/3/2019 between 19:04 and 19:18 UTC above north-east Thailand and central Thailand, north of Bangkok, between $\left(21.08^{\circ}, 102.98^{\circ}\right)$ and $\left(14.96^{\circ}, 101.59^{\circ}\right)$. Along the same path above the Gulf of Thailand and southern Thailand near Malaysia, there were thick layers of smoke aerosol interspersed with marine aerosol layers above ground to $2.5 \mathrm{~km}$ high. Figure 13(c), on 16/3/2019 between 5:55 to 6:10 UTC, shows layers of smoke aerosol high above marine aerosol layers above the East Sea (or South China Sea). And Figure 13(d), on 17/4/2019 between 6:20 and 6:33 UTC, there are some thick layers of smoke aerosols from 1 to $5 \mathrm{~km}$ high above northern Cambodia and central Laos. The MODIS hot spots and AOD data provide the spatial pattern of fire sources and particle dispersion above ground while CALIPSO lidar provides a snapshot of the vertical distribution of aerosols from the ground up to $20 \mathrm{~km}$.

Smoke aerosols are detected, in all the lidar profiles in Figure 13, above the location corresponding to the sources (Figure 13a, 13b and 13d) as well as above the East Sea off the coast between Vietnam and the Philippines (Figure 13c). The smoke layers varied between above ground level up to $5 \mathrm{~km}$. To assess the WRF-Chem prediction, comparison with CALIPSO aerosol vertical profiles are made. The predicted vertical profiles of Total $\mathrm{BC}$ (hydrophilic and hydrophobic $\mathrm{BC}$ ), $\mathrm{PM}_{2.5}$ along the paths corresponding to the CALIPSO satellite paths (15/3/2019 19:00 and 16/3/2019 6:00 UTC) are extracted from the WRF-Chem output and are shown in Figure 14. The lidar data provides the distribution of smoke aerosols above ground, the top height at which the smoke aerosols reach in the atmosphere and the extent of the smoke plume along the path where the satellite pass above the smoke aerosol clouds. There is a correspondence between the predicted profiles of Total $\mathrm{BC}, \mathrm{PM}_{2.5}$ and $\mathrm{PM}_{10}$ with CALIPSO satellite lidar observation. On 15/3/2019 19:00 UTC, the predicted $B C, \mathrm{PM}_{2.5}$ and $\mathrm{PM}_{10}$ layers are from 0 to $\sim 6 \mathrm{~km}$ high 
(Figure 14a) and the observed CALIPSO smoke aerosol layers were at similar height (max $\sim 5 \mathrm{~km}$ ) and at similar location on the satellite path (Figure 13b). Similarly, on 16/3/2019 6:00 UTC, the predicted BC, $\mathrm{PM}_{2.5}$ and $\mathrm{PM}_{10}$ layers are between approximately $\sim 2.5 \mathrm{~km}$ to $3 \mathrm{~km}$ high with $\mathrm{PM}_{10}$ intruded to ground level located at about $\left(22.9^{\circ}, 113.2^{\circ}\right)$ as in Figure 14b. The observed CALIPSO profile (Figure 13c) also have smoke layers at similar height approximately between $2.5 \mathrm{~km}$ to $3 \mathrm{~km}$ and the intrusion of $\mathrm{PM}_{10}$ smoke aerosols to ground level was found at similar location as in the predicted $\mathrm{PM}_{10}$ profile.

Vertical profile of wind and aerosols

The biomass burnings during the 13 to 19 March 2019 period mostly occurred in the highland and mountainous areas. To understand the effect of pollutant transport and dispersion due to the high location effect, it is best to analyse the vertical profile of wind and aerosol concentration over time. The two vertical profiles along the paths passing through Luang Namtha and Ubon Ratchathani (red horizontal lines in Figure 4d) are shown in Figure 15 and 16.

Most fires occurred in highland and mountainous areas during the simulation period. As shown in Figure 15 of predicted vertical profile passing through Luang Namtha, the fires effect on the $\mathrm{PM}_{2.5}$ ground concentration in the coastal Red River delta of north Vietnam is not significant (10 to $20 \mu \mathrm{g} / \mathrm{m} 3$ ). However, the plume $\mathrm{PM}_{2.5}$ concentration at $2 \mathrm{~km}$ height is high (90 to $130 \mu \mathrm{g} / \mathrm{m} 3$ ) and the dispersion to southern China (near Hainan island) is widespread up to $7 \mathrm{~km}$ above sea level.

Similarly, further down south near the end of the Truong Son mountain range, the vertical profile from the Dawna Mountain range in east of Thailand to Central Highland of Vietnam passing through Ubon Ratchathani shows that biomass burnings occurred in the Dawna Range in Khao Laem National Park and in the Central Highland of Vietnam. In between of the Dawna Range and Central Highland is the central lowland plain and Chao Phraya River basin where there was no, or little biomass burnings as shown in Figure 16 below. High concentration of $\mathrm{PM}_{2.5}$ on surface and up to $6 \mathrm{~km}$ above ground where the burnings occurred in Dawna Range in the east and Central Highland in the west. However, high concentration of $\mathrm{PM}_{2.5}$ in smoke plumes above the lowland areas of central Thailand also present. At time, especially on 17 to 19 March 2019, the high concentration above central Thailand plain extend down to ground level ( 90 to $110 \mu \mathrm{g} / \mathrm{m}^{3}$ ). The aerosols plumes above the central plain came from the biomass burnings in northern Thailand. They were transported by northernly wind at height from $4 \mathrm{~km}$ to $8 \mathrm{~km}$ above ground. Intrusion of smoke plumes to ground levels occurred and caused elevated concentration levels of $\mathrm{PM}_{2.5}$.

\section{Discussion}

The results of our study using WRF-Chem simulation have shown that the biomass burnings in insular SEA during 13 to 19 March 2019 had a large impact on regional transport of air pollutants, emitted from the fires, affecting air quality, especially in Thailand and Laos. Due to the Truong Son mountain range running along the Laos and Vietnam border from the Yunnan province in China to the Central Highlands 
of Vietnam, the biomass burning in Laos and Northeast Thailand did not cause significant transport and impact on ground level aerosols concentration in Vietnam. The mountain range however acts as a launching pad for transport of smoke aerosols to higher atmospheric levels and hence facilitated the long-range transport of air pollutants beyond Vietnam to southern China and the Philippines when the prevailing wind is either westerly or south westerly as Lin et al., 2009 has identified in their study of transport mechanism of pollutants from biomass burnings in Indochina. They reported that both thermal effect and dynamic forcing resulting from mountain lee-side effect enhance the upward motion of aerosols and pollutants from biomass burnings up to above $3 \mathrm{~km}$ and under westerly winds these pollutants are transported to Taiwan and beyond to the rest of East Asia. In our study, nearly all the biomass burnings happened in the highland or mountain areas which facilitated the wide dispersion and transport of emitted pollutants from the burnings. We also have shown that the surface wind on insular SEA was mostly northerly and north-easterly during the period 13 to 19 March 2019 and hence high surface concentration of aerosols such as $\mathrm{PM}_{2.5}$ from the biomass burnings were confined in the vicinities of the fires in northern Laos, northern and north eastern Thailand and the downwind areas in central Thailand. Upper winds however are of different patterns compared to that on ground level, and hence dispersion of pollutants at pressure levels less than $850 \mathrm{hPa}$ (height above $\sim 1500 \mathrm{~m}$ ) showed the pollutants transported across Thailand, Cambodia, Laos, Vietnam and to southern China.

Our study used FINN emission inventory of biomass burnings and NCEP FNL reanalysis meteorological data as input to the air quality model to assess the transport and dispersion of pollutants in SEA. These datasets were also previously used by other studies (Xing et al, 20020, Takami et al. 2020, Lin et al. 2014). One of the reasons for choosing FINN because of the high spatial and temporal resolution of its emission data (Paton-Walsh et al. 2011). Xing et al. 2020 in their study of source contribution to the 2017 annual mean of Elemental Carbon (EC) in Thailand using WRF-Chem simulation have shown that biomass burning contributed $6.1 \%$ to the annual mean EC concentrations on the ground while anthropogenic emissions (including the industry, power plant, residential, and transportation sectors) contributed $75.1 \%$. Even though the biomass burnings contribution to EC annual mean is less than anthropogenic sources but the highest concentration occurred in spring and in mountainous northwest areas of Thailand where intense biomass burnings occurred at the end of the dry season in spring. Their study also showed that local emission in Thailand contributed $81.2 \%$ of EC annual mean while regional transport outside Thailand contributed only $18.8 \%$. Similar to our study, to account for biomass emission, they used FINN emission data over similar modelling domain. Takami et al. 2020 used WRF-CMAQ model rather than WRF-Chem to study the impact of biomass burning on $\mathrm{PM}_{10}$ concentration in Indochina. They use NCEP FNL and ERA-Interim reanalysis global meteorological data as input to the WRF mesoscale model to produce meteorological data for CMAQ air quality model simulation. For emission data, the FINN from NCAR and GFED (Global Fire Emission Database) based on MODIS products emission inventories of fires were used in their CMAQ simulation of $\mathrm{PM}_{10}$. They found that NCEP FNL and FINN v1.5 (FNL + FINN) performed best in simulation of $\mathrm{PM}_{10}$ when compared with observation. Our study also shows that using WRF-Chem air quality model with NCEP FNL Reanalysis meteorological data and FINN 
v1.5 emission data provides reasonable results in assessing the effect of biomass burnings in South East Asia on regional air quality.

Our focus is the effect of biomass burnings in the whole insular SEA region and outside regions in term of pollution transport of $\mathrm{PM}_{2.5}$ and $\mathrm{BC}$ and air quality both on surface and above surface level. Hence predicted and observed AODs are used to both evaluate model performance and to assess the impact of biomass burnings throughout the region. AOD satellite observed data can be used to determine the sources of aerosols causing high AOD in a region. Nguyen et al. 2019 recently use AOD from satellite and from AERONET sites to study the spatial-temporal pattern of air quality over SEA. They found a strong correlation between AOD from ground AERONET and MODIS AOD $\left(R^{2}=0.81\right)$ as well as VIIRS AOD $\left(R^{2}=0.68\right)$ from satellites and that seasonal variation of $A O D$ in mainland SEA has peak AOD in MarchApril and then second AOD peak in September-October. The secondary peak AOD in September-October is due to aerosol transport to mainland SEA from forest fires in maritime SEA (Indonesia). Huang and Lin (2015), in their study on sources of fine mode aerosols in SCS using empirical orthogonal function (EOF) on AOD data, identified the main sources of fine mode aerosols as coming from Indochina (mainland SEA) during March and April and Sumatra and Borneo (maritime SEA) from August to September annually. These periods reflect the biomass burnings in those regions. They also found that during $\mathrm{El}$ Nino years the average amplitude of fine mode AOD is higher and suggested that is possibly due to the change in wind direction in tropical SEA and hence the distribution of aerosols. AOD data from AERONET has the advantage of higher temporal resolution while satellite AOD has better spatial coverage. They are both valuable in assessing the air quality model performance for simulation of emission and dispersion of pollutants from wildfires and dust storms over a large domain. Chang et al. 2015, without resorting to modelling, used only MODIS satellite products such as AOD, BA (Burned Area), FC (Fire count) over a number of years to study the spatial-temporal of $A O D$ in relation to the biomass burnings in mainland and maritime SEA.

Our simulation study included the anthropogenic emission sources such as land and shipping transport based on global EDGAR-HTAP dataset. As the simulation period is when the most intense of the biomass burnings in March 2019 occurred, the contribution of anthropogenic emission to aerosol dispersion and concentration at ground and above ground level is much lower than the emission from biomass burnings as shown in the spatio-temporal patterns of surface and vertical profiles of $\mathrm{PM}_{2.5}$ concentration in the domain. Yin et al., 2019 used Positive Matrix Factorization (PMF) with AOD from MODIS sensor, CO from MOPITT (Measurement of Pollution in the Troposphere) sensor on Terra satellite and $\mathrm{PM}_{2.5}$ from MERRA Aerosol Reanalysis (MERRAero) model from 2001 to 2016 have shown that during March the biomass burnings contributed most to the aerosols in SEA. Even though the AOD seasonal patterns over SEA show annual peaks in March-April and in September-October due to biomass burnings, but each year the burnings have considerable variance in their onset, duration, and intensity from year to year (Cohen \& Lecoeur, 2015). In this respect, our impact study of the 2019 biomass burnings from 13 to 19 March 2019 showed particular characteristics of the pollutant transport and its impact on air quality in mainland SEA driven by meteorological condition during this period. 
The use of CALIOP lidar onboard CALIPSO satellite to obtain the aerosol profile is useful in comparing with predicted aerosols and $\mathrm{BC}$ profile from air quality model or with other type of ground-based measurements (Campbell et al. 2013, Tsay et al. 2013). In our study, the predicted $\mathrm{PM}_{2.5}$ and BC profiles corresponds reasonably with CALIPSO aerosol type profile along the satellite paths during the study period. In additional to horizontal columnar AOD data for model verification, the aerosol vertical profiles are also necessary to assess the performance of the air quality model.

There are some limits and uncertainties in the current simulation study using WRF-Chem. There are uncertainties in the emission input from NCAR FINN which is based on sources of biomass burnings from hot spots detection from MODIS satellites. Not all sources can be detected even the use of VIIRS (Visible Infrared Imaging Radiometer Suite) from Suomi NPP satellite at $375 \mathrm{~m}$ high resolution can improve the accounting of all sources. But the twice daily satellite overpass limits the temporal coverage and the current model does not account for fire behaviour progress. The emission factors for different pollutant species emitted from biomass burnings is also one of the uncertainties which include misidentification of the land cover, inaccurate fuel loading. The uncertainty in emission estimates is about a factor of two (Wiedinmyer et al., 2010). The meteorological component WRF used the widely available NCEP global reanalysis data which give good results in many applications of air quality modelling. As for chemistry component in the WRF-Chem, the process of chemical transformation and reactions during transport is complex that usually can be captured in air quality model using a variety of different chemical mechanism. However, for BC, an important particle component of emission from biomass burnings, Zhang et al. 2019 has recently studied the aging process of BC during transport in which the coating of $\mathrm{BC}$ core aerosols with chemicals evolved during aerosol transport and chemical process from emission sources. This process is not yet accounted for in the chemistry mechanism implemented in WRF-Chem.

In term of exposure and health effect on population, the most affected areas are in Thailand, especially the northern part of Thailand where there is high population and elevated $\mathrm{PM}_{2.5}$ concentration occurred. The prevailing northernly and north easterly wind flow carried the emitted pollutants from northern and north-eastern biomass burnings to the south and south west populated area of Thailand. Northern Laos also experienced high concentration of $\mathrm{PM}_{2.5}$ and extensive smoke plumes but the area has low population density. The health impacts on population exposure in Laos therefore are expected to be less than those in Thailand. Vietnam has high population density compared to Laos, Cambodia and Thailand but the aerosol concentration due to biomass burnings is lower and hence the exposure would be less.

Exposure to $\mathrm{PM}_{2.5}$ has detrimental health outcomes especially in high risk groups, such as those with cardio-respiratory disease, with elevated morbidity and mortality associated with exposure to $\mathrm{PM}_{2.5}$ and BC. Presently, adverse health impacts due directly to BC is inconclusive, however increases in hospital admissions during high smoke periods is evident (WHO 2012, Salimi et al. 2017, Janssen et al. 2011). Marlier et al. 2013, in their study of the health risks from landscape fire emissions in SEA from 1997 to 2006 using satellite data and modelling to quantify health effects, have shown that during strong El Niño years, an estimated $10,800(6,800-14,300)$ person $(\sim 2 \%)$ annual increase in regional adult 
cardiovascular mortality. Fires (agricultural burnings and forest fires) in SEA have a large impact on air quality and public health in the region.

\section{Conclusion}

Biomass burnings at the end of the dry season in South East Asia are major sources of particles including BC which not only affect air quality, health but also climate warming. Other large sources of biomass burnings are in South America, Africa and Indian sub-continent. This study uses the remote sensing data and WRF-Chem model to show the extent of the effect of biomass burnings in SEA at the end of the dry season in March 2019 on ground level and in the upper levels of the atmosphere. At the ground level, the concentration of $\mathrm{PM}_{2.5}$ due to biomass burnings in SEA, mainly concentrated in Thailand and Laos, did not affect much Vietnam as the Truong Son mountain range acts as an effective barrier but it allows the pollutants to be lifted at higher levels and hence enables the transport of smoke pollutants further afield to southern China, Taiwan and beyond.

The evolution of predicted vertical profiles of wind and aerosols concentration over time show that the emission of aerosols from biomass burnings in SEA, especially occurring in the highland and mountainous areas are transported at high level above ground. Long-range transport of pollutants from biomass burnings shows that the effect is not only regional but also interregional, including Taiwan, East Sea (South China Sea) and southern China. Modelling results show that the predicted AOD and AOD AERONET measurements on ground corresponded reasonably well across the modelling domain and that there is evidence of intrusion of smoke clouds to ground levels at some location as shown by simulation results and from lidar CALIOP profile of aerosol types onboard CALIPSO.

The biomass burnings annually at the end of the dry season in SEA caused widespread pollution at the local and regional wide scale. It is important to account for the effects of burnings on population. Policy or coordinated action taken by regional countries to minimise the human health cost should be considered regarding the timing and meteorological conditions for burnings at the end of the dry season in SEA. Our future work will focus on epidemiology study to estimate the health impact due to biomass burnings in SEA.

\section{Declarations}

Data availability statement: The datasets generated during and/or analysed during the current study are available from the corresponding author on reasonable request.

Author Contributions: Conceptualisation, H.N. ; methodology, H.N.; data procurement: H.N, B.H. T.D; formal analysis, H.N., Q.N, Q.N.; investigation, H.N., B.H.; writing-original draft preparation, H.N, B.H, T.D; visualisation, H.N.; supervision, H.N. and Q.N.; and project administration, H.N.

Funding: This research received no external funding. 
Acknowledgments: The MERRA-2 data used in this study/project were provided by the Global Modeling and Assimilation Office (GMAO) at NASA Goddard Space Flight Center. CALIPSO satellite products were from NASA Langley Research Center (http://www-calipso.larc.nasa.gov/products/lidar/browse_ images/production/). The TMPA data were provided by the NASA/Goddard Space Flight Center's Mesoscale Atmospheric Processes Laboratory and PPS, which develop and compute the TMPA as a contribution to TRMM.

For AERONET data, we thank the Principal Investigators and Co-Investigators and their staff for establishing and maintaining the 4 sites used in this investigation.

Conflicts of Interest: The authors declare no conflict of interest.

\section{References}

Andrea, M., Merlet, P., 2001, Emission of trace gases and aerosols from biomass burning, Global Biogeochemical Cycles, 15 (4): 955-966

Aouizerats, B., van der Werf, G., Balasubramanian, Betha, R., 2015, Importance of transboundary transport of biomass burning emissions to regional air quality in Southeast Asia during a high fire event, Atmos. Chem. Phys., 15, 363-373, 2015, www.atmos-chem-phys.net/15/363/2015/, doi:10.5194/acp-15-3632015

Broome, R.; Johnston, F.; Horsley, J.; Morgan, G., 2016, A rapid assessment of the impact of hazard reduction burning around Sydney, May 2016. Med. J. Aust., 205, 407-408, doi:10.5694/mja16.00895.

Campbell, J., Reid, J., Westphal, D. et al., 2013, Characterizing the vertical profile of aerosol particle extinction and linear depolarization over Southeast Asia and the Maritime Continent: The 2007-2009 view from CALIOP, Atmospheric Research, 122:520-543.

Cavazos-Guerra, C.; Todd, M, 2012, Model Simulations of Complex Dust Emissions over the Sahara during the West African Monsoon Onset. Adv. Meteorol., 2012, 351731

Chang, C., Hsiao, Y., Huang, C., 2015, Evaluating Spatial and Temporal Variations of Aerosol Optical Depth and Biomass Burning over Southeast Asia Based on Satellite Data Products, Aerosol and Air Quality Research, https://doi.org/10.4209/aaqr.2015.10.0589

Crippa, M., Solazzo, E., Huang, F., et al., 2020, High resolution temporal profiles in the Emissions Database for Global Atmospheric Research, Scientific Data, Vol. 7: 121 | https://doi.org/10.1038/s41597-020-04622

Cohen, J., Lecoeur, E., 2015, Decadal-scale relationship between measurements of aerosols, land-use change, and fire over Southeast Asia, Atmospheric Chemistry \& Physics. 15:26895-26957. 
Deng, X., Tie, X., Zhou, X., et al., 2008, Effects of Southeast Asia biomass burning on aerosols and ozone concentrations over the Pearl River Delta (PRD) region, Atmospheric Environment, 36:84938501, https://doi.org/10.1016/j.atmosenv.2008.08.013

Duc, H., Ho, B., Ngo, Q., 2016, Modelling and prediction of air pollutant transport during the 2014 biomass burning and forest fires in peninsular Southeast Asia, Environ Monit. Assess., 188:106 DOI 10.1007/s10661-016-5106-9

Duc, H., Chang, L., Azzi, M., Jiang, N., 2018, Smoke aerosols dispersion and transport from the 2013 New South Wales (Australia) bushfires, Environmental Monitoring and Assessment, DOI: 10.1007/s10661-0186810-4

Field, R., van der Werf, G., Fanin, T., 2016, Indonesian fire activity and smoke pollution in 2015 show persistent nonlinear sensitivity to El Niño-induced drought, PNAS, 113:92049209, https://doi.org/10.1073/pnas.1524888113

Fountoukis, C., Ackermann, L., Ayoub, M.A., Gladich, I., Hoehn, R.D, Skillern, A., 2016, Impact of atmospheric dust emission schemes on dust production and concentration over the Arabian Peninsula. Model. Earth Syst. Environ., 2016, 2, 115.

Huang, K., Fu, J., Hsu, C., et al., 2013, Impact assessment of biomass burning on air quality in Southeast and East Asia during BASE-ASIA, Atmospheric Environment, 78:201-302

Huang, S., Lin, C., 2015, Distribution of Atmospheric Aerosol over the South China Sea, Advances in Meteorology, vol. 2015, https://doi.org/10.1155/2015/692762

Janssens-Maenhout, G. et al., 2015, HTAP_v2.2: a mosaic of regional and global emission grid maps for 2008 and 2010 to study hemispheric transport of air pollution. Atmos. Chem. Phys. 15, 11411-11432, https://doi.org/10.5194/acp-15-11411-2015 (2015).

Janssen, N., Hoek, G., Simic-Lawson, M., Fischer, P., et al., 2011, Black Carbon as an additional indicator of the adverse health effects of airborne particles compared with $\mathrm{PM}_{10}$ and $\mathrm{PM}_{2.5}$. Environ. Health Perspect., 119, 1691-1699, doi:10.1289/ehp.1003369.

Kong, S., Chuang, M., Ooi, M., Huang, W., Lin, N., 2018, Simulating the impact of East Asia Dust Event during the Spring Season on Taiwan: A Testing of the New Windblown Dust Module in CMAQ, Presented at the $16^{\text {th }}$ Annual CMAS Conference, Chapel Hill, NC, Oct. 22-24, 2018, https://www.cmascenter.org/conference//2018/abstracts/kong_simulating_impact_2018.pdf

Lin, C., Zhao, C., Liu, X., et al., 2014, Modelling of long-range transport of Southeast Asia biomass-burning aerosols to Taiwan and their radiative forcings over East Asia, Tellus B: Chemical and Physical Meteorology, https://doi.org/10.3402/tellusb.v66.23733 
Lin C., Hsu H., Lee Y., et al, 2009, A new transport mechanism of biomass burning from Indochina as identified by modeling studies. Atmos. Chem. Phys., 9: 7901-7911.

Lloyd, C., Sorichetta, A. \& Tatem, A., 2017, High resolution global gridded data for use in population studies, Sci Data 4, 170001. https://doi.org/10.1038/sdata.2017.1

Marlier, M., DeFries, R., Voulgarakis, A., et al., 2013, El Niño and health risks from landscape fire emissions in southeast Asia, Nature Clim Change 3, 131-136 (2013). https://doi.org/10.1038/nclimate1658

Nguyen, T., Pham, H., Lasko, K., et al., 2019a, Spatiotemporal analysis of ground and satellite-based aerosol for air quality assessment in the Southeast Asia region, Environmental Pollution, https://doi.org/10.1016/j.envpol.2019.113106

Nguyen, H., Riley, M.; Leys, J.; Salter, D., 2019b, Dust Storm Event of February 2019 in Central and East Coast of Australia and Evidence of Long-Range Transport to New Zealand and Antarctica. Atmosphere 2019, 10, 653. https://doi.org/10.3390/atmos10110653

Paton-Walsh, C., Emmons, L., Wiedinmyer, C., 2012, Australia's Black Saturday fires - Comparison of techniques for estimating emissions from vegetation fires, Atmospheric Environment, 60:262-170

Randerson, J., van der Werf, G., Giglio, L., Collatz, G. and Kasibhatla, P., 2018. Global Fire Emissions Database, Version 4.1 (GFEDv4). ORNL DAAC, Oak Ridge, Tennessee, USA. https://doi.org/10.3334/ORNLDAAC/1293

Salimi, F., Henderson, S., Morgan, G., Jalaludin, B., Johnston, F., 2017, Ambient particulate matter, landscape fire smoke, and emergency ambulance dispatches in Sydney, Australia. Environ. Int., 99, 208212, doi:10.1016/j.envint.2016.11.018.

Takami, K., Shimadera, H., Uranishi, K., Kondo, A., 2020, Impacts of biomass burning emission inventories and atmospheric reanalyses on simulated $\mathrm{PM}_{10}$ over Indochina, Atmosphere, 11(2), 160; https://doi.org/10.3390/atmos11020160

Tsay, S., Hsu, C., Lau, W., et al., 2013, From BASE-ASIA toward 7-SEAS: A satellite-surface perspective of boreal spring biomass-burning aerosols and clouds in Southeast Asia, Atmospheric Environment 78, DOI: 10.1016/j.atmosenv.2012.12.013

Vadrevu, P., Lasko, K., Giglio, L. Justice, C., 2014, Analysis of Southeast Asian pollution episode during June 2013 using satellite remote sensing datasets, Environmental Pollution, 195:245256, https://doi.org/10.1016/j.envpol.2014.06.017

WHO (World health Organization), 2012, Health Effects of Black Carbon; WHO Regional Office for Europe: Geneva, Switzerland, 
Wiedinmyer, C., Akagi, S., Yokelson R., et al., 2010, The Fire INventory from NCAR (FINN): a high resolution global model to estimate the emissions from open burning, Geoscientific Model Development Discussions. 3: 2439-2476

Xing, L., Li, G., Pongpiachan, S., et al., 2020, Quantifying the contributions of local emissions and regional transport to elemental carbon in Thailand, Environmental Pollution, 262:114272, DOI:

10.1016/j.envpol.2020.114272

Yin, S., Wang, X., hang, X., et al., 2019, Influence of biomass burning on local air pollution in mainland Southeast Asia from 2001 to 2016, Environmental Pollution, Vol. 254, Part A, 112949, https://doi.org/10.1016/j.envpol.2019.07.117

Zhang, Y., Li, M., Cheng, Y., et al. 2019, Modeling the aging process of black carbon during atmospheric transport using a new approach: a case study in Beijing, Atmos. Chem. Phys., 19, 9663-9680, https://doi.org/10.5194/acp-19-9663-2019

Zhao, C.; Liu, X.; Leung, L.R.; Hagos, S., 2011, Radiative impact of mineral dust on monsoon precipitation variability over West Africa., Atmos. Chem. Phys. Discuss. 2011, 11, 1879-1893

\section{Figures}
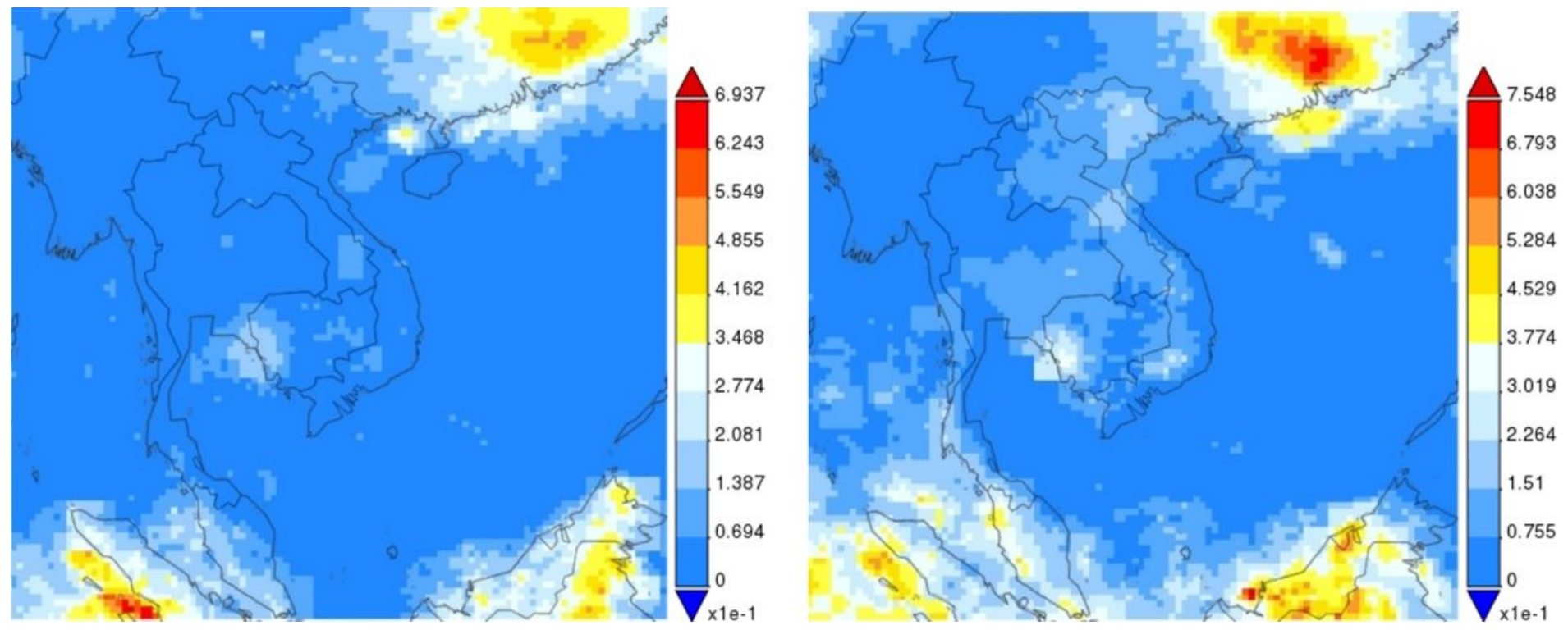

Figure 1

TRMM monthly average precipitation in March (left) and April 2019 (right) over South East Asia at 0.250 $x 0.25$ o resolution from TRMM Multi-satellite Precipitation Analysis (TMPA) 3B43 product. The scale unit is $\mathrm{mm}$ rainfall per hour (source: https://giovanni.gsfc.nasa.gov). 

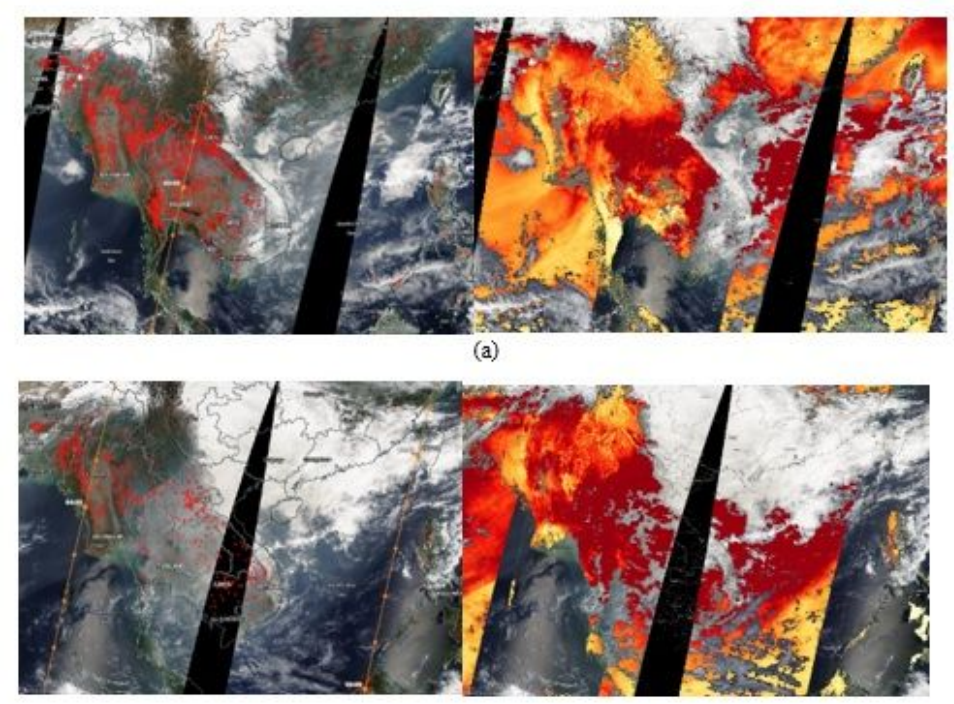

(b)

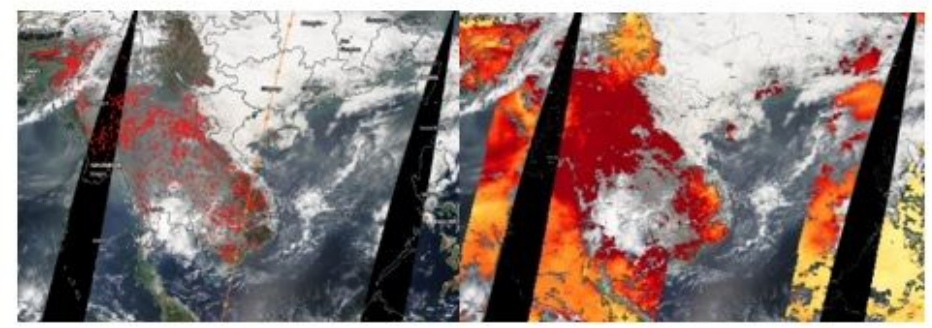

(c)

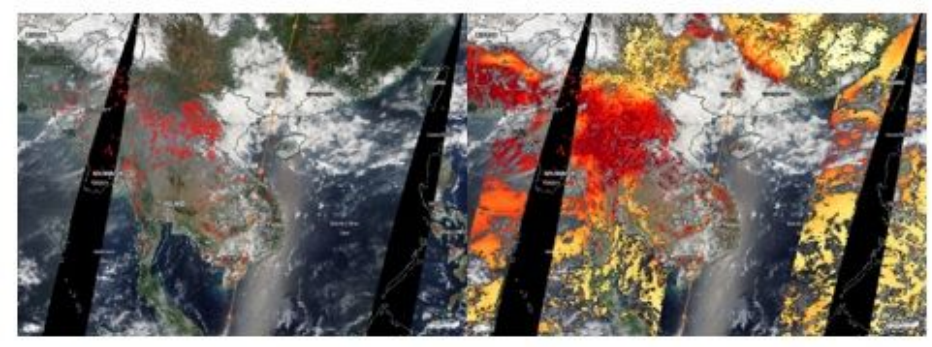

(d)

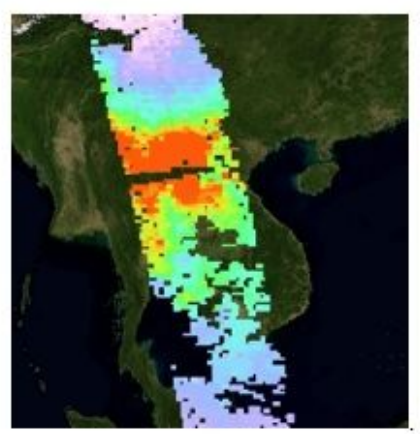

Figure 2

Hot spots and Aerosol Optical Depth (AOD) on 12 (a), 15 (b) and 16/3/2019 (c) and 17/4/2019 (d) over South East Asia. Columnar CO as measured by MOPITT sensor on Terra satellite (e). High concentration of $\mathrm{CO}$ (orange red) are located above northern Thailand where most fires occurred. 

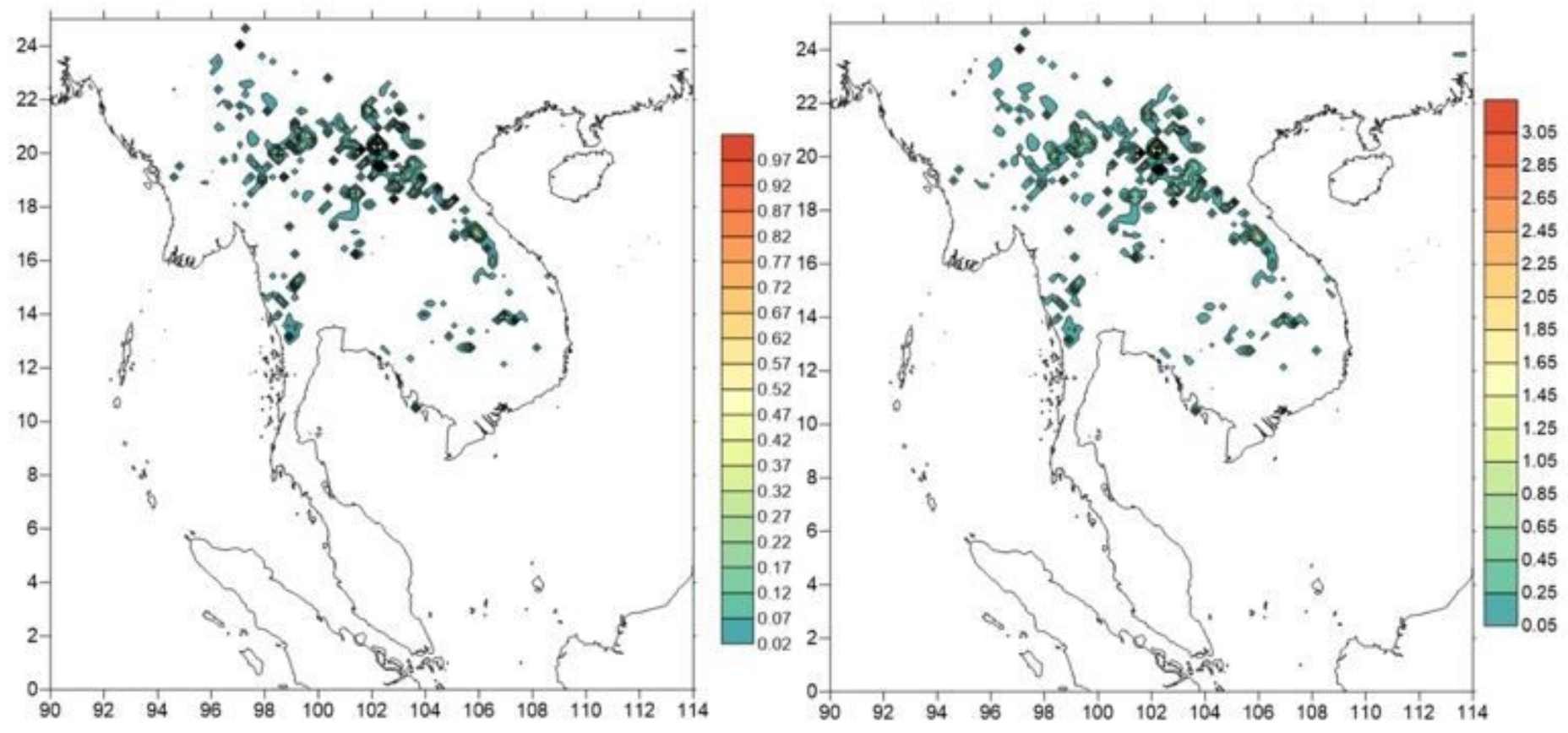

Figure 3

BC and PM2.5 emission ( $\mu \mathrm{g} \mathrm{m}-2 \mathrm{~s}-1$ ) from fires on 14 March 2019 at 16:00 UTC as estimated by FINN 
WRF Domain Configuration

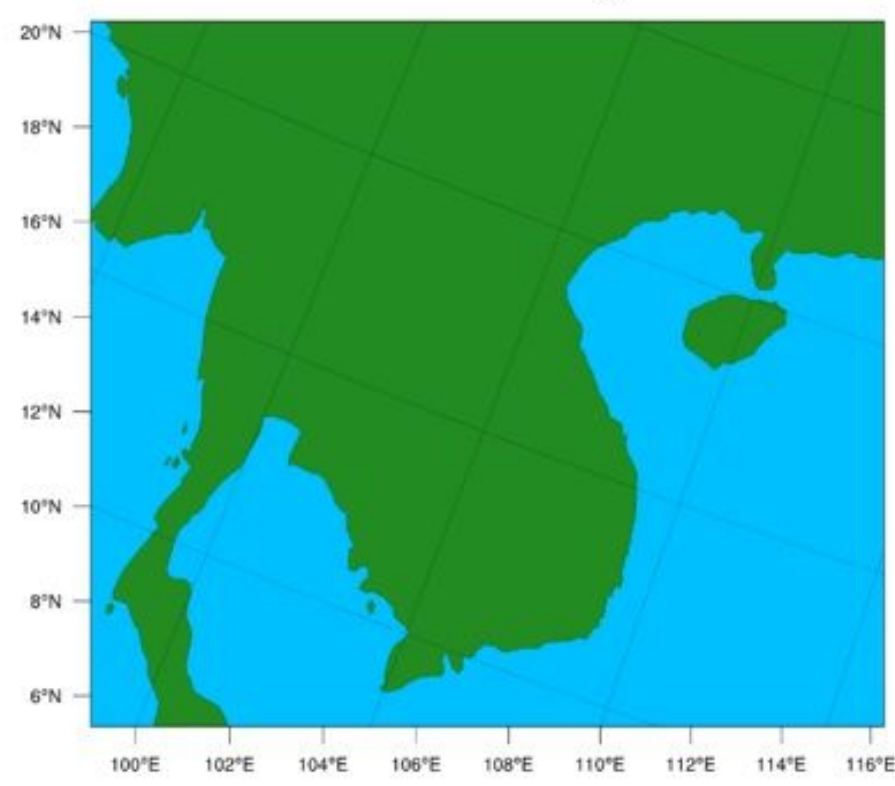

Topography of the modelling domain

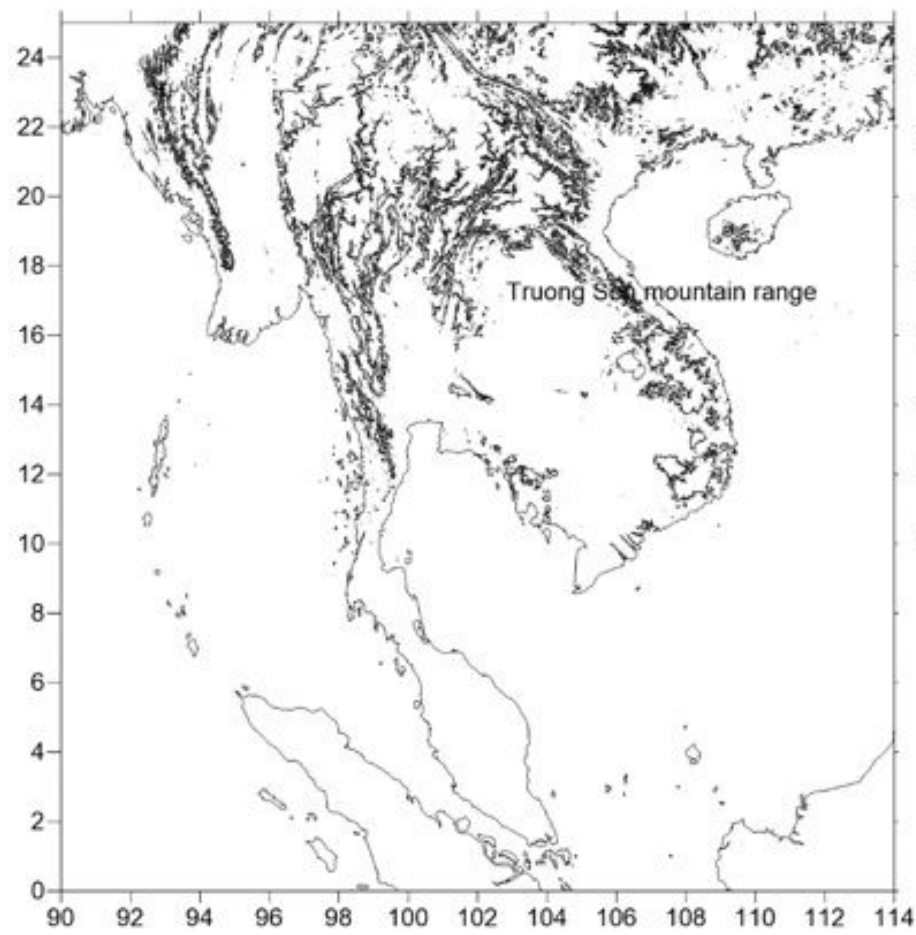

CO emission (mol/km²/hr) from anthropogenic sources (EDGAR-HTAP)

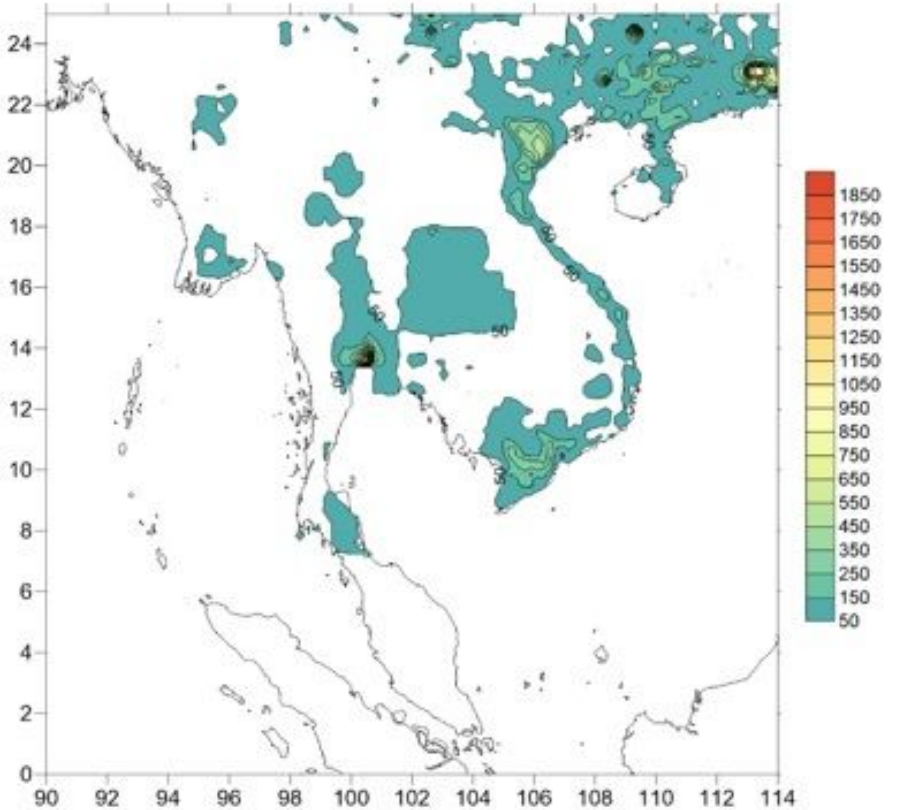

\section{AERONET study sites}

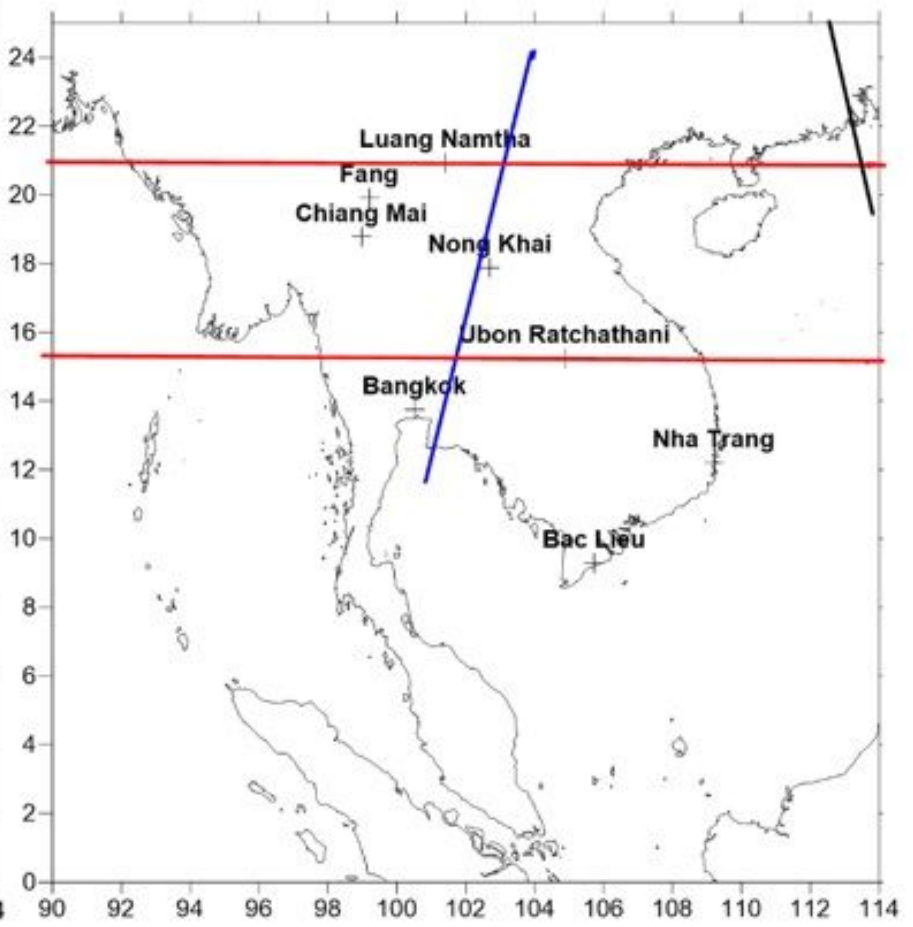

\section{Figure 4}

(a) WRF-Chem modelling domain (b) Anthropogenic daily emission of $\mathrm{CO}$ for $14 / 3 / 2019$ as obtained from EDGAR-HTAP emission data set at $0.10 \times 0.10$ resolution (c) Topography of the modelling domain with Truong Son mountain range running along the border of Laos and Vietnam. (d) AERONET sites, Chiang Mai, Luang Namtha, Fang, Nong Khai, Ubon Ratchathani, Bangkok (Thailand), Nha Trang and Bac Lieu (Vietnam) and vertical profile paths of CALIPSO satellite (blue and black) and profiles of simulated 
wind and aerosol concentration (red) to be analysed in the study. Simulation period is from 13/3/2019 to 19/3/2019 period which corresponds to high AOD as measured from AERONET sites.
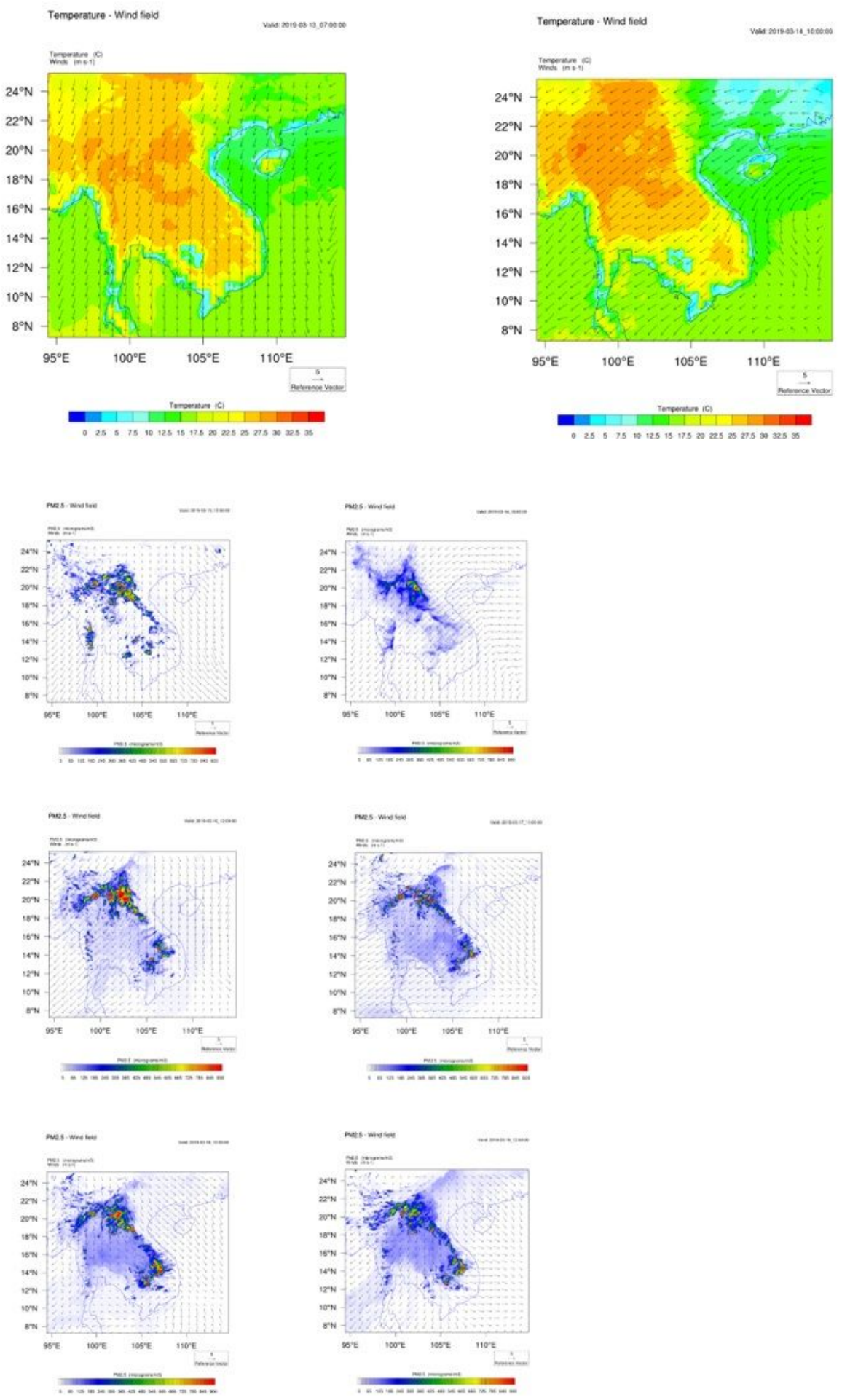

\section{Figure 5}

Predicted surface temperature and wind field on 13/3/2019 07:00 UTC and on 14/3/2019 10:00 UTC. Surface wind field and predicted PM2.5 ground concentration $(\mu \mathrm{g} / \mathrm{m} 3)$ on 13/3/019 12:00 UTC, 

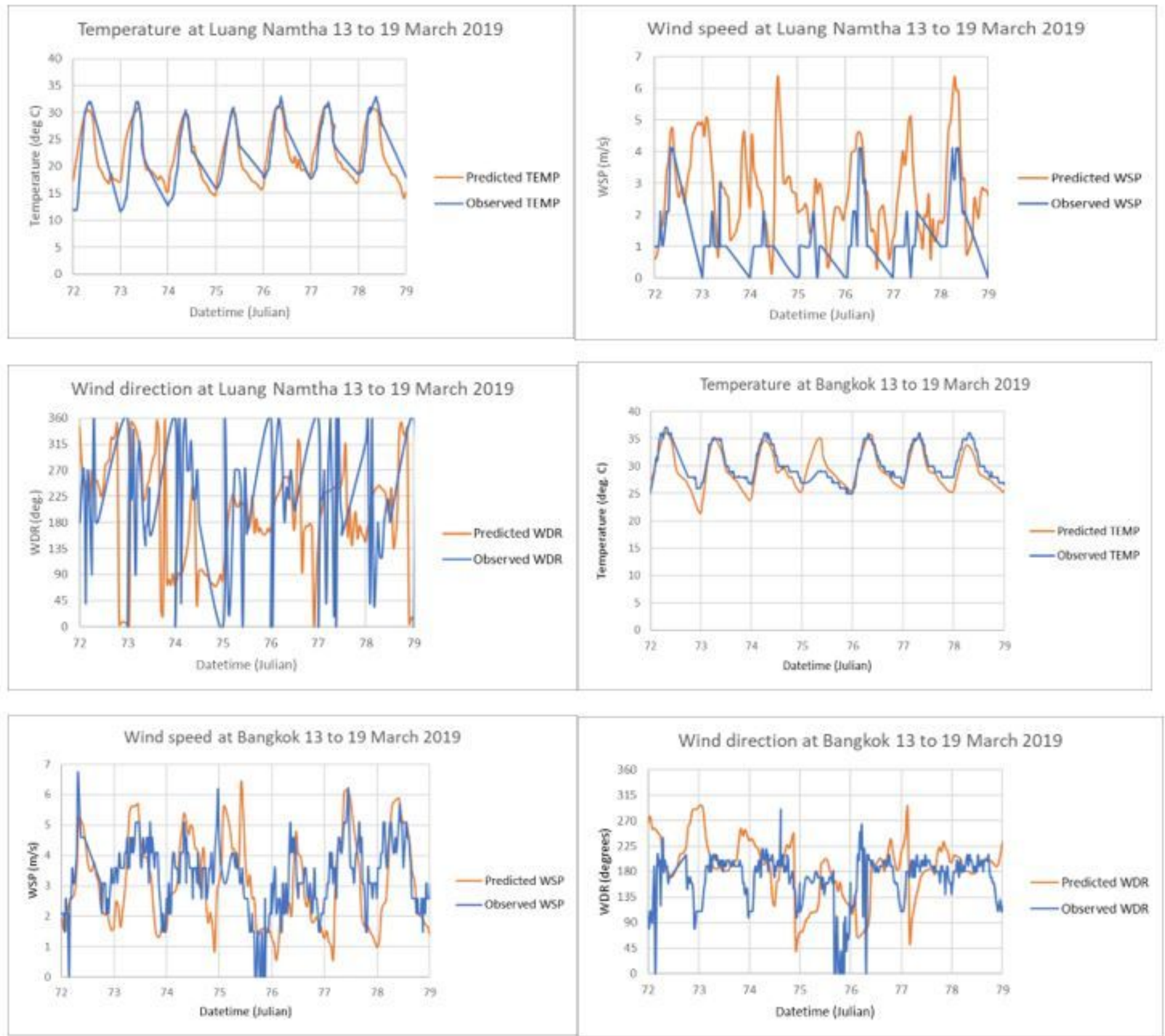

\section{Figure 6}

Predicted temperature, wind speed and wind direction as compared to observed data at Luang Namtha (northern Laos) and Bangkok (central Thailand). 

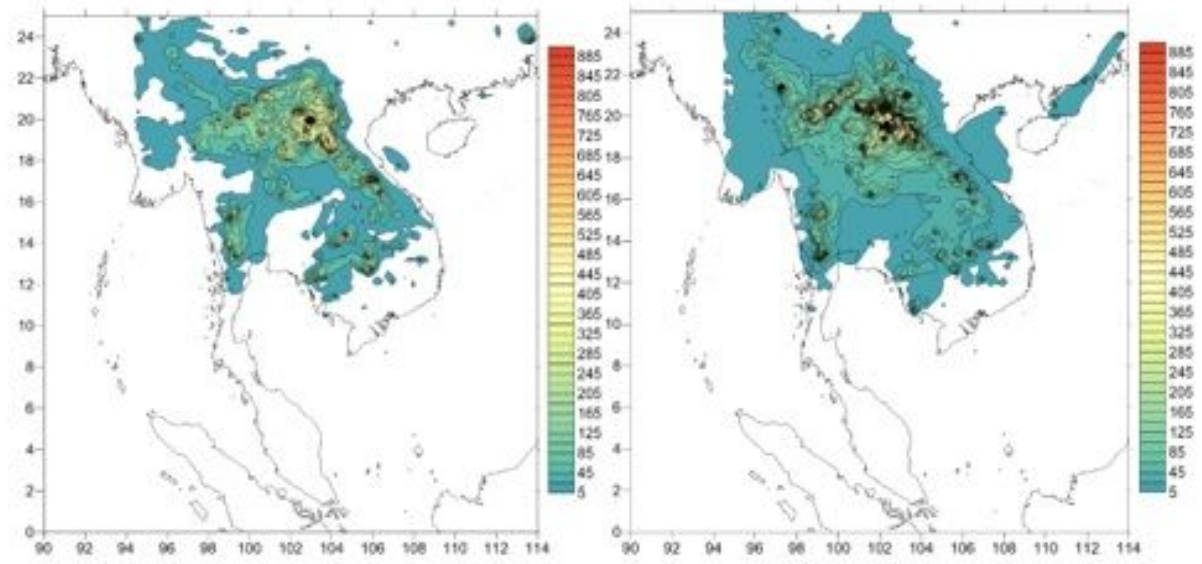

Predicted daly average of PN/2.5 ground cencentation $\left(\mathrm{pg}^{3} \mathrm{~m}^{3}\right)$ 15/32019

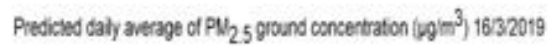
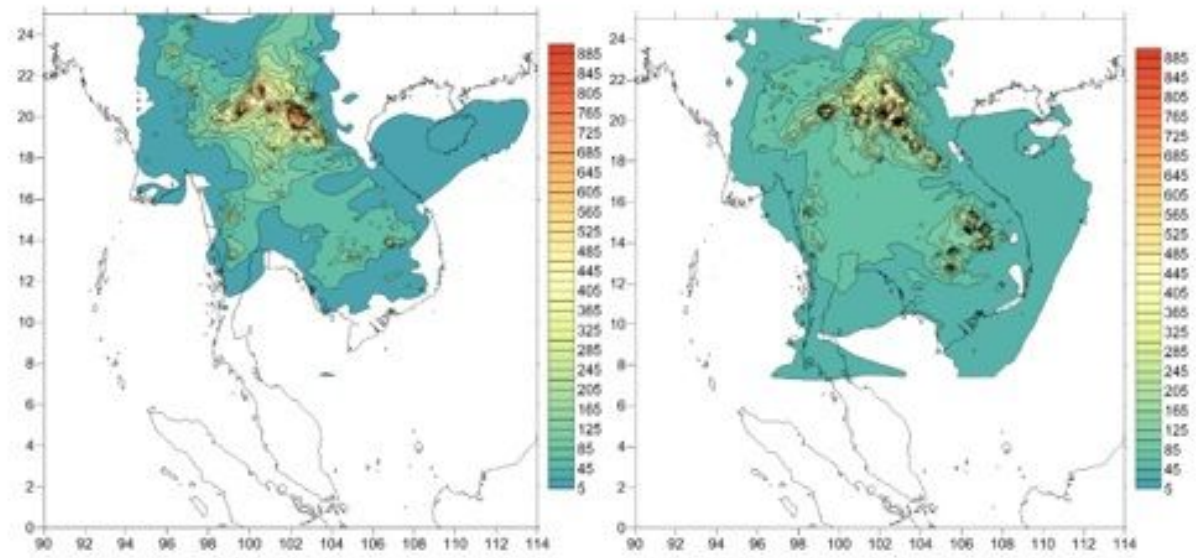

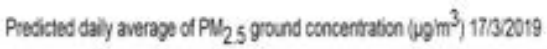

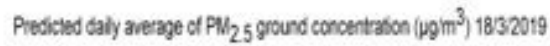
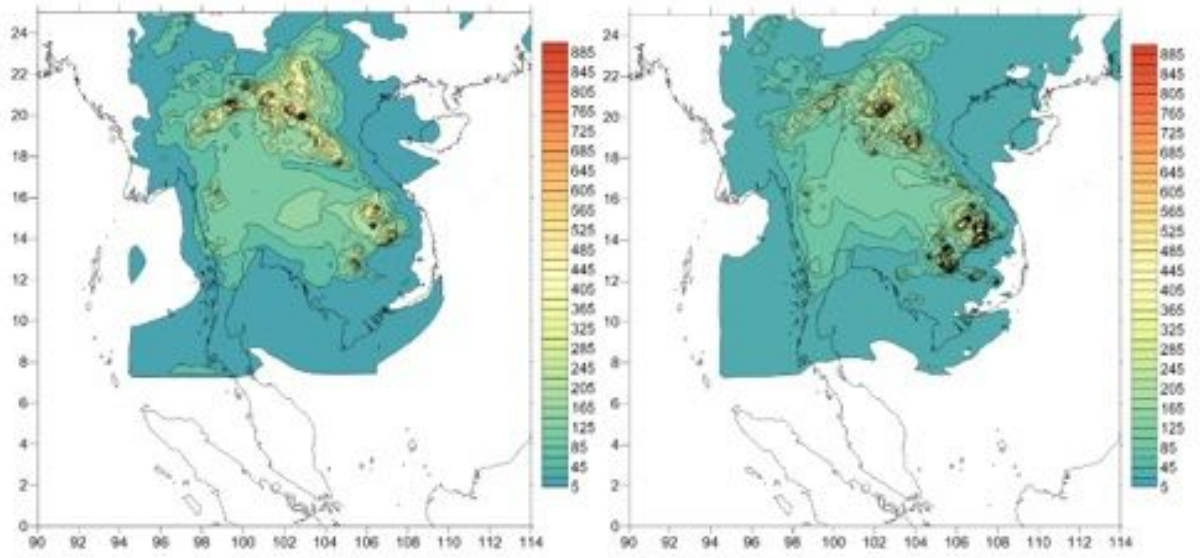

\section{Figure 7}

Predicted ground concentration of daily average PM2.5 $(\mu \mathrm{g} / \mathrm{m} 3)$ due to biomass burnings for the period from 13 to 18 March 2019 when the burnings was most intense and the extend of the smoke cloud as measured by MODIS AOD is most extensive. 
Predicted daily average of $\mathrm{PM}_{2.5}$ concentration $\left(\mu \mathrm{g} / \mathrm{m}^{3}\right)$ Predicted daily average of $\mathrm{PM}_{2.5}$ concentration $\left(\mu \mathrm{g} / \mathrm{m}^{3}\right)$

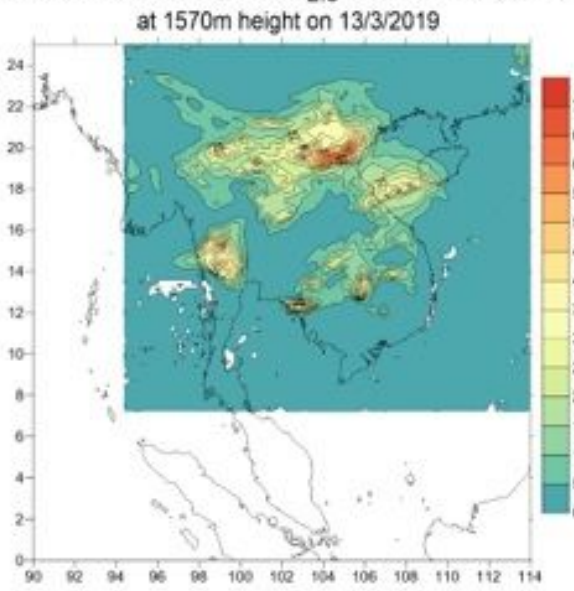
at $1570 \mathrm{~m}$ height on $14 / 3 / 2019$

Predicted daily average of $\mathrm{PM}_{2.5}$ concentration $\left(\mu \mathrm{g} / \mathrm{m}^{3}\right)$ Predicted daily average of $\mathrm{PM}_{2.5}$ concentration $\left(\mu \mathrm{\mu g} / \mathrm{m}^{3}\right.$ )
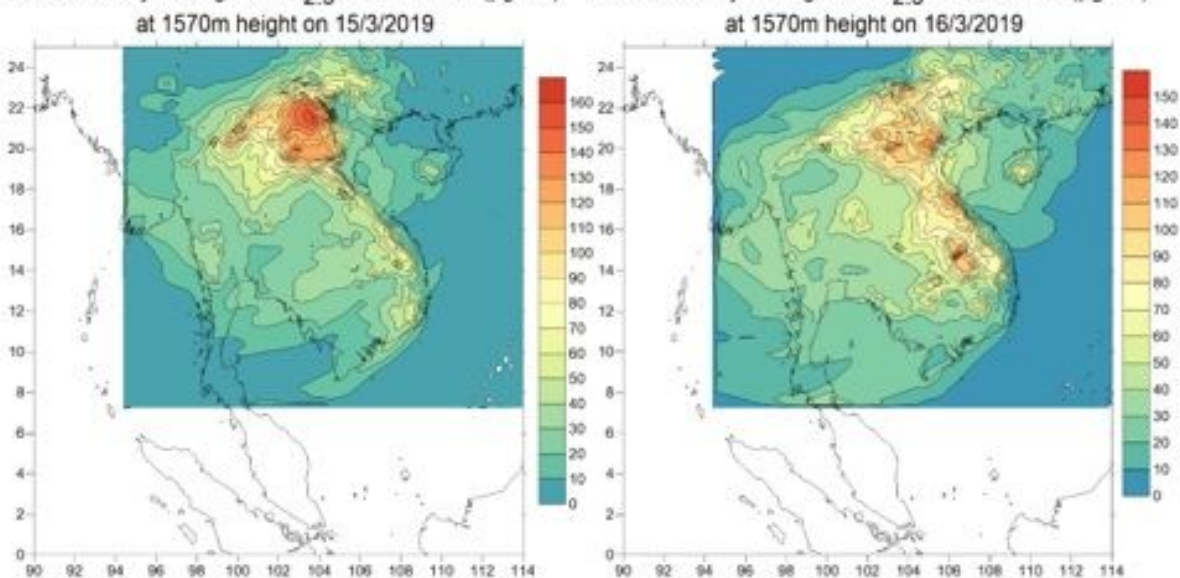

Predicted daily average of $\mathrm{PM}_{2.5}$ concentration $\left(\mu \mathrm{g} / \mathrm{m}^{3}\right)$ at $1570 \mathrm{~m}$ height on $17 / 3 / 2019$

Predicted daily average of $\mathrm{PM}_{2.5}$ concentration $\left(\mu \mathrm{g} / \mathrm{m}^{3}\right)$

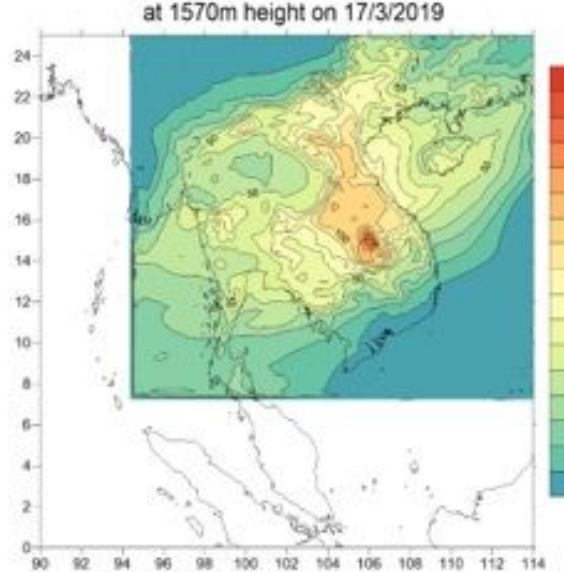
at $1570 \mathrm{~m}$ height on $18 / 3 / 2019$

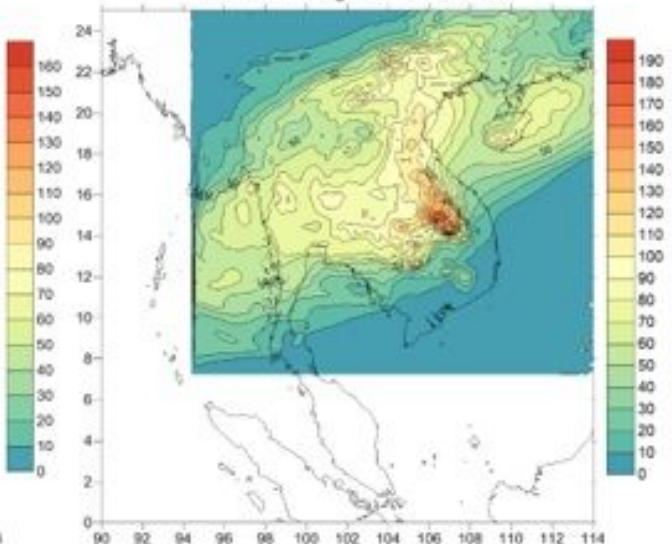

\section{Figure 8}

Predicted daily average PM2.5 concentration at $1570 \mathrm{~m}$ (level 10 of 32 levels in WRF model configuration) for 13 to 18 March 2019. 

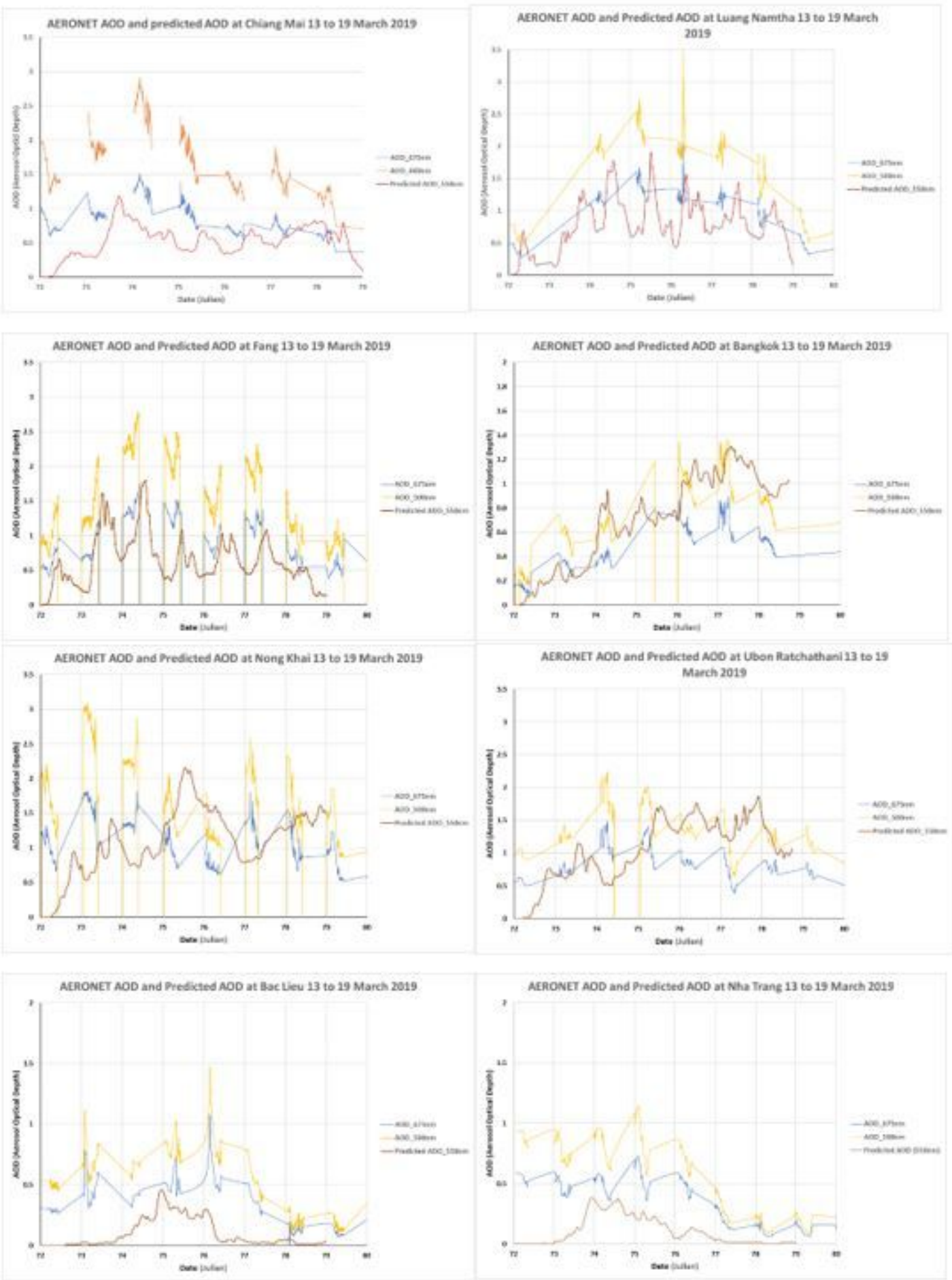

\section{Figure 9}

Predicted AOD time series as compared to observed AOD from AERONET sites, at Chiang Mai, Luang Namtha (Laos), Nong Khai, Fang, Bangkok in Thailand and Bac Lieu and Nha Trang in Vietnam. 

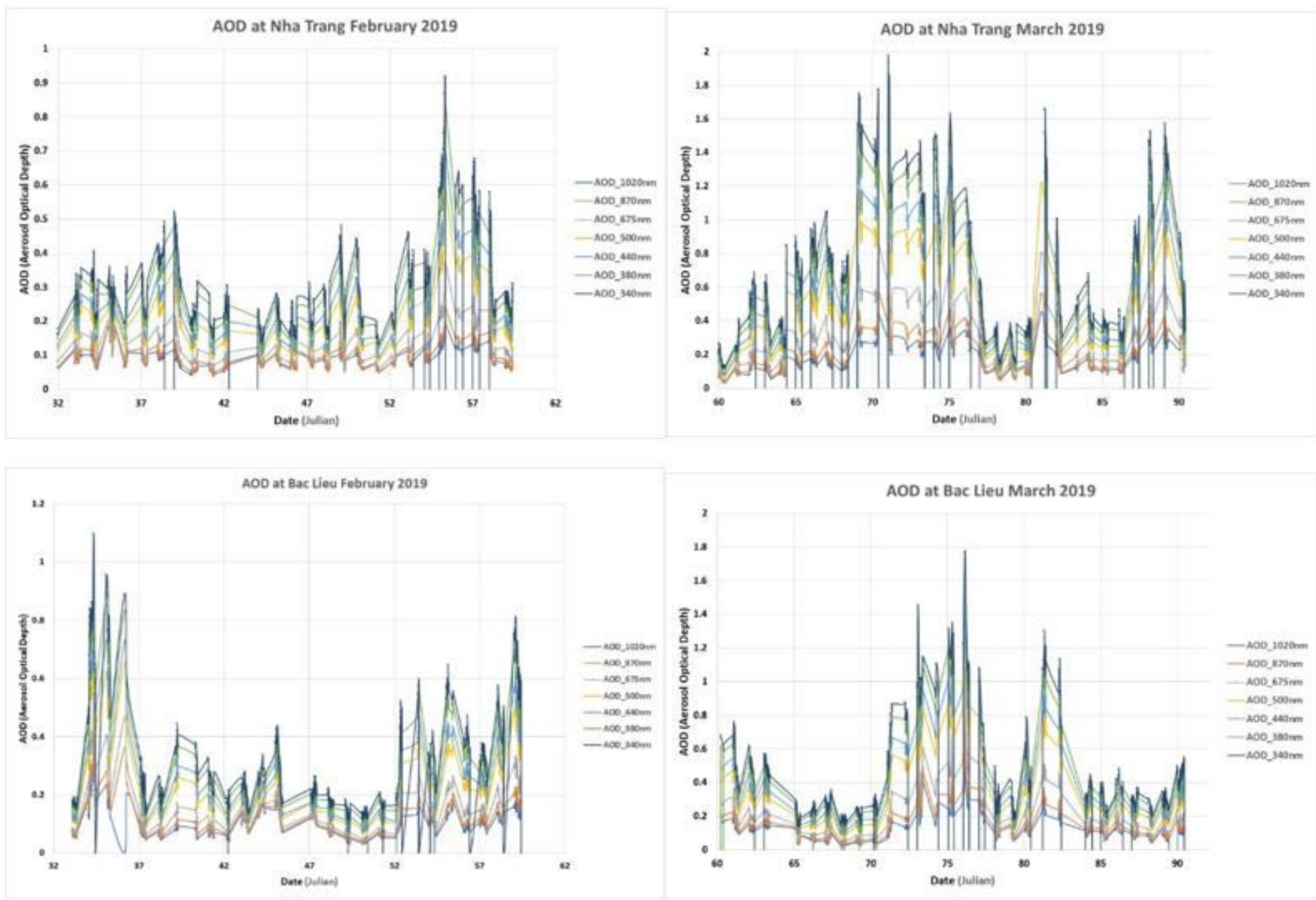

Figure 10

AOD during February and March 2019 as measured at Nha Trang, Bac Lieu from AERONET network.

Predicted AOD 14 March 2019 00:00 UTC

Predicted AOD 17 March 2019 00:00 UTC
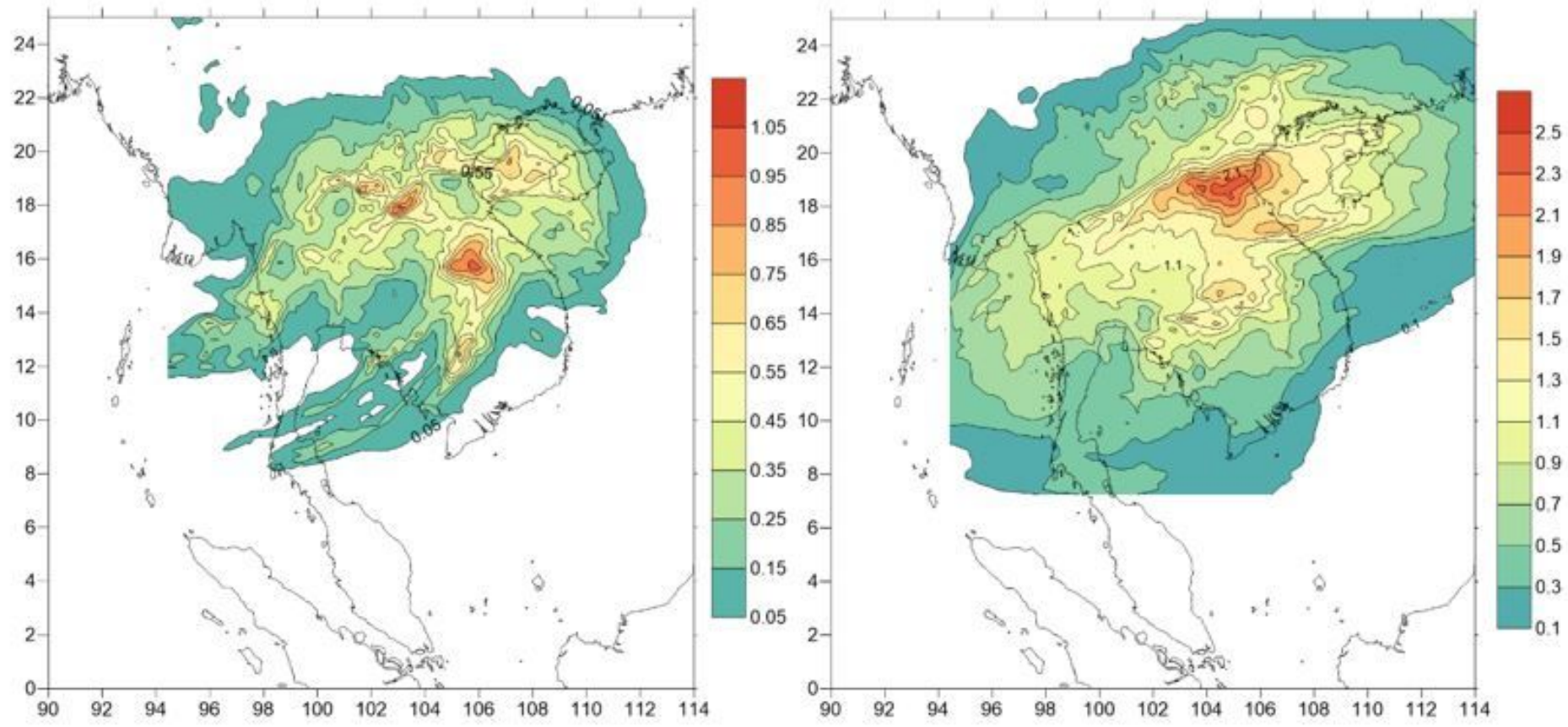


\section{Figure 11}

Predicted AOD on 14 March 2019 00:00 UTC and on 17 March 2019 00:00 UTC show the extend of the aerosols across mainland SEA and southern China due to biomass burnings. High AOD occurs in northeast Thailand, Laos, northern Cambodia.

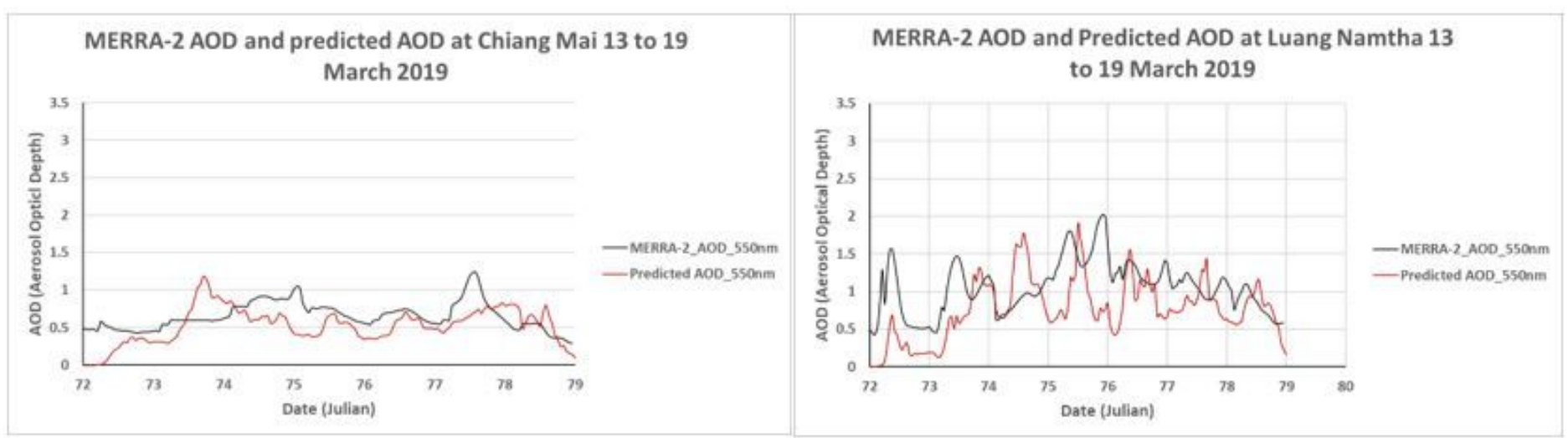

Figure 12

MERRA-2 Total Aerosol Extinction AOT prediction at 550nm as compared to predicted AOD 550nm from WRF-Chem at Chaing Mai and Luang Namtha. 


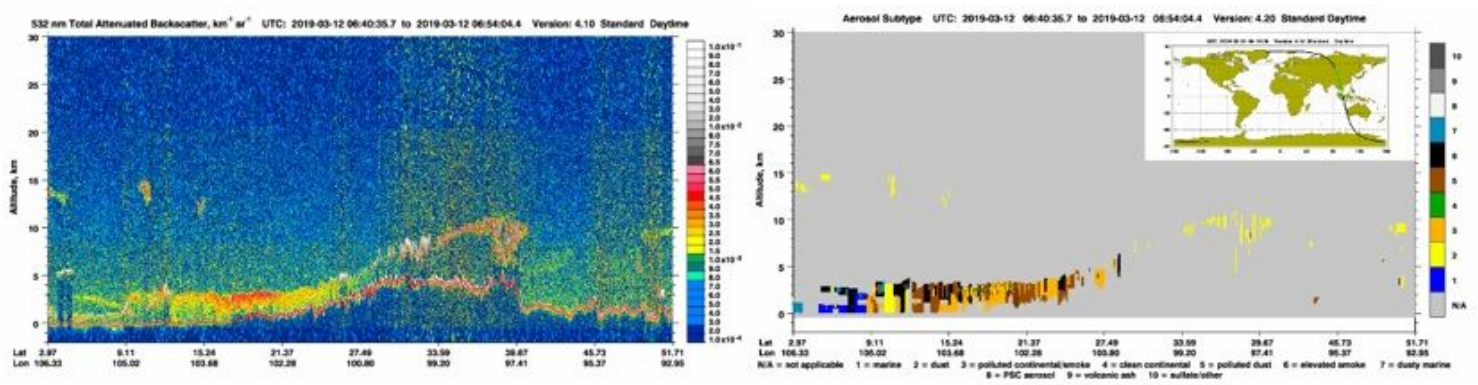

(a)

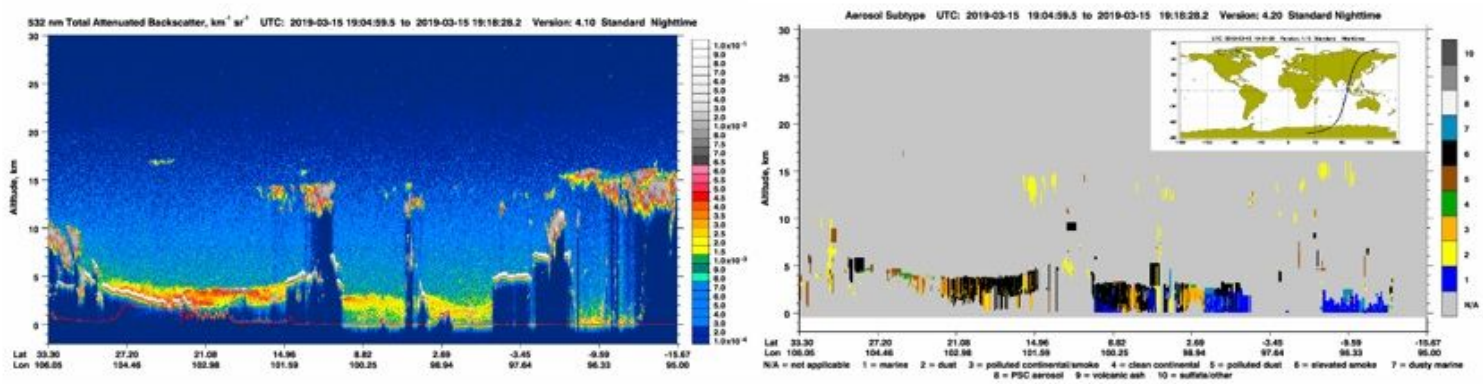

(b)

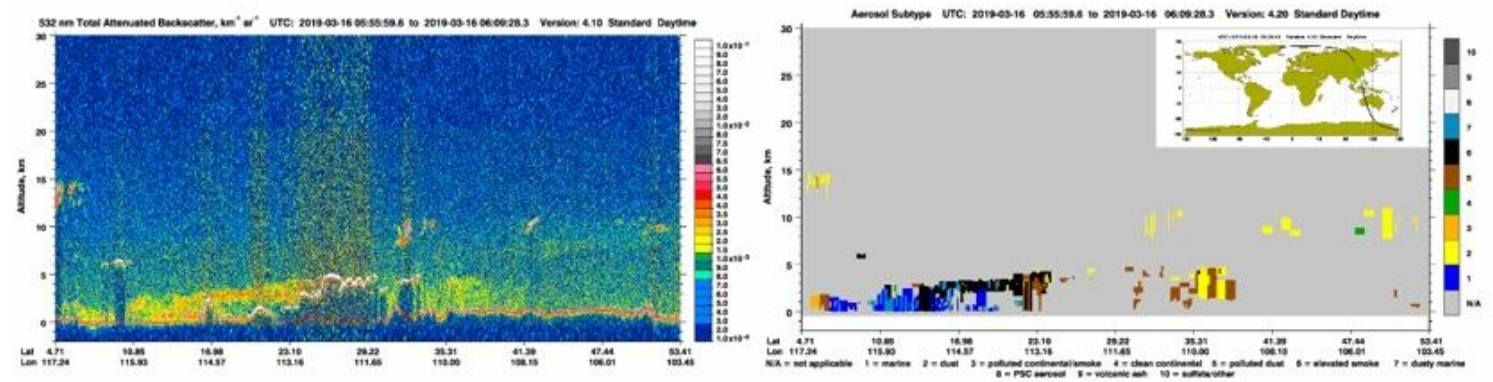

(c)
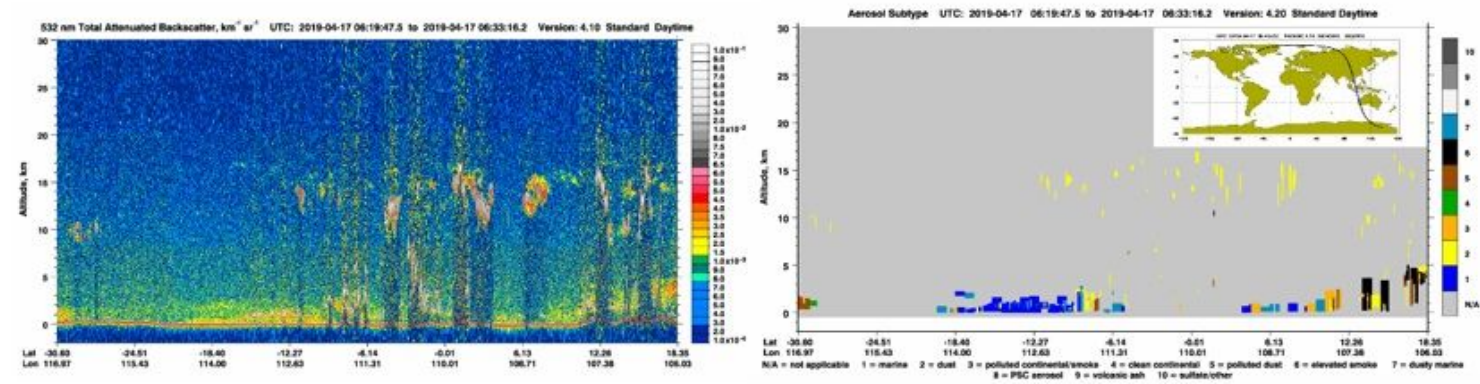

(d)

\section{Figure 13}

Total attenuated backscatter (km-1 sr-1) and aerosol subtype profile from CALIPSO on 12 March 2019 (a), 15 March 2019 (b), 16 March 2019 (c) and 17 April 2019 (d) across South East Asia (Inset in each figure is the CALIPSO satellite path). The aerosol subtypes are marine (blue), dust (yellow), polluted continental/smoke (orange), clean continental (green), polluted dust (brown), elevated smoke (black), 
dusty marine (cyan), PSC (polar stratospheric clouds) aerosol (white), volcanic ash (light grey), sulfate/other (grey).
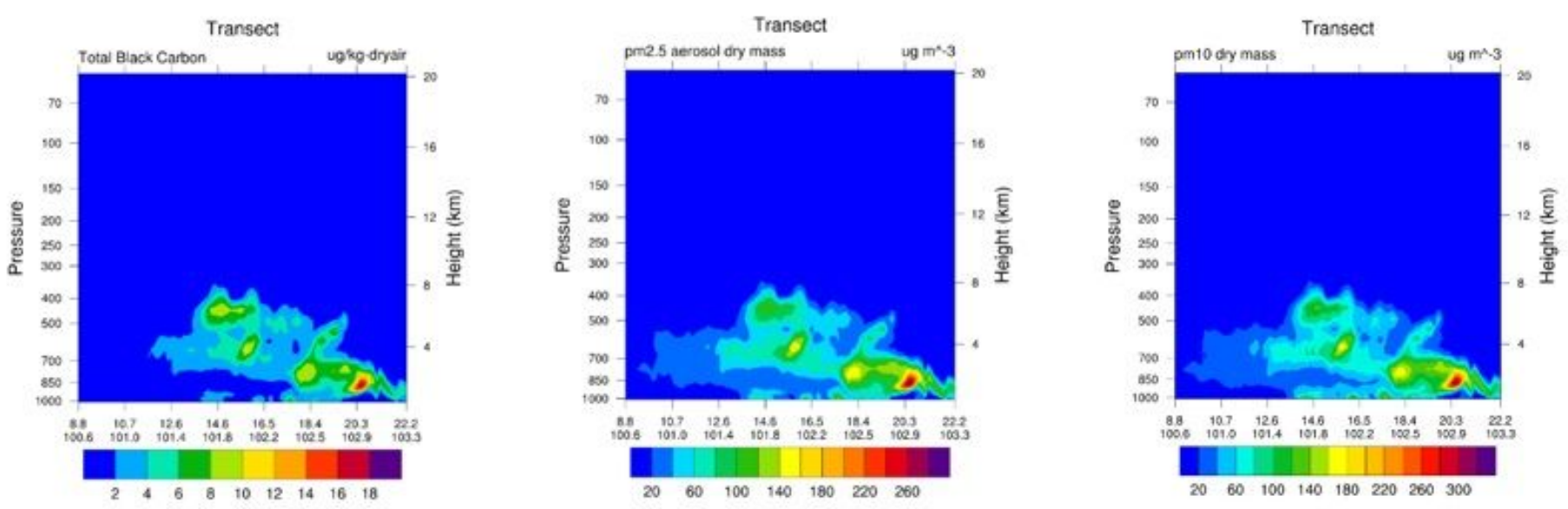

(a)
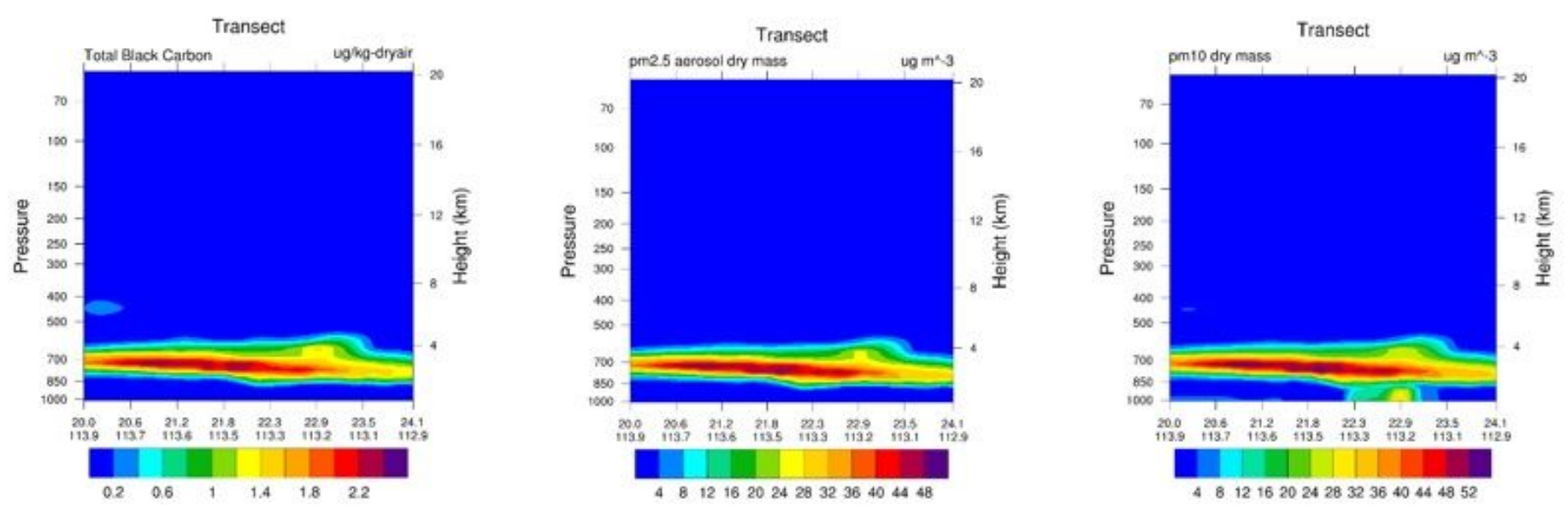

(b)

\section{Figure 14}

Predicted profiles of Total BC, PM2.5 and PM10 along the satellite path on 15 March 2019 19:00 UTC (a) on 16 March 2019 6:00 UTC (b) 

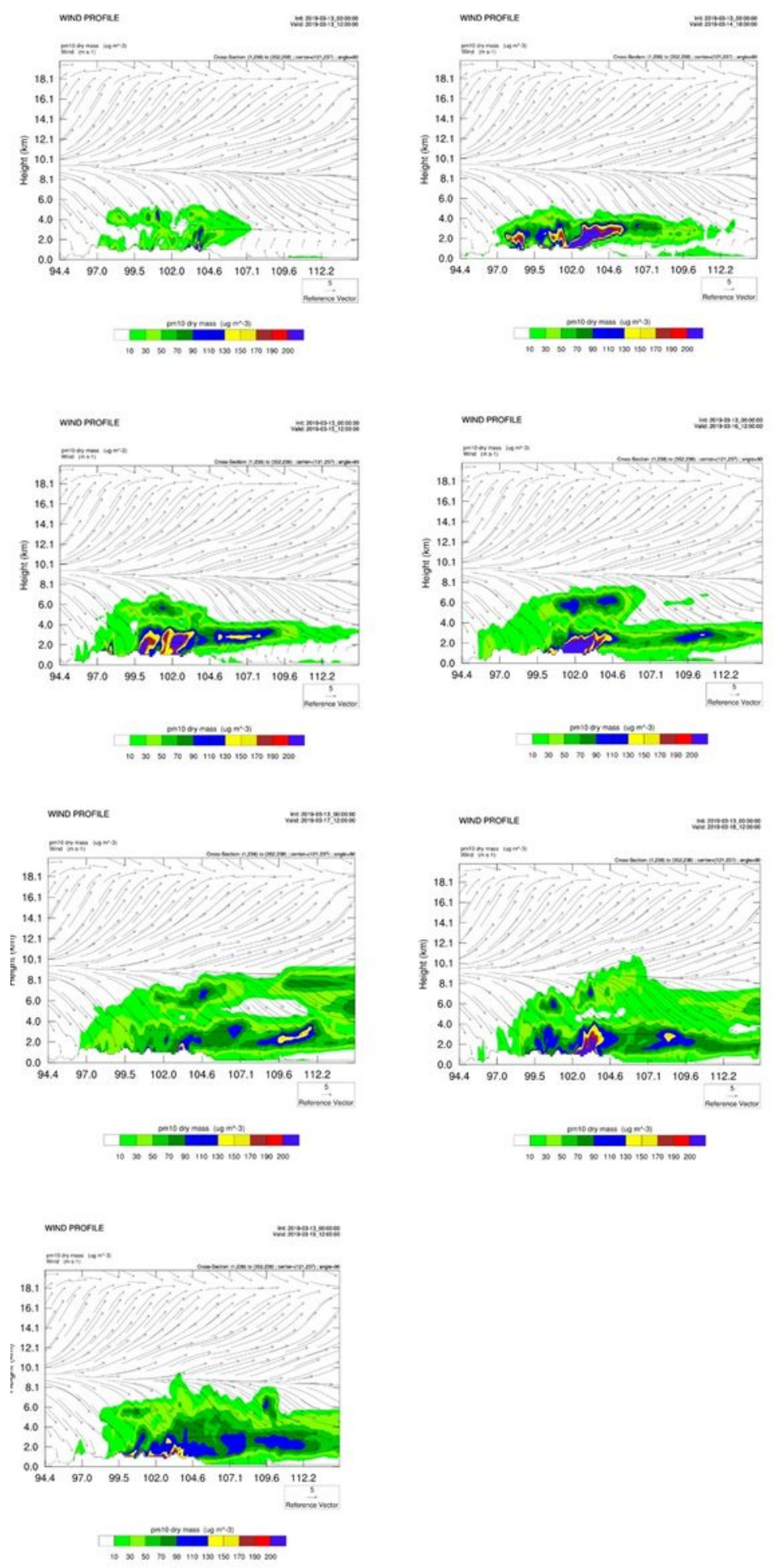

\section{Figure 15}

Predicted vertical profiles of wind and PM2.5 concentration along the path passing through Luang Namtha on 13/3/2019 12:00, 14/3/2019 18:00, 15/3/2019 12:00, 16/3/2019 12:00. 17/3/2019 12:00 and 19/3/2019 12:00 UTC. The outline of the highland and mountains can be seen up to $2 \mathrm{~km}$ high from 94.40 to 1060 longitude at the bottom along the horizontal axes. 

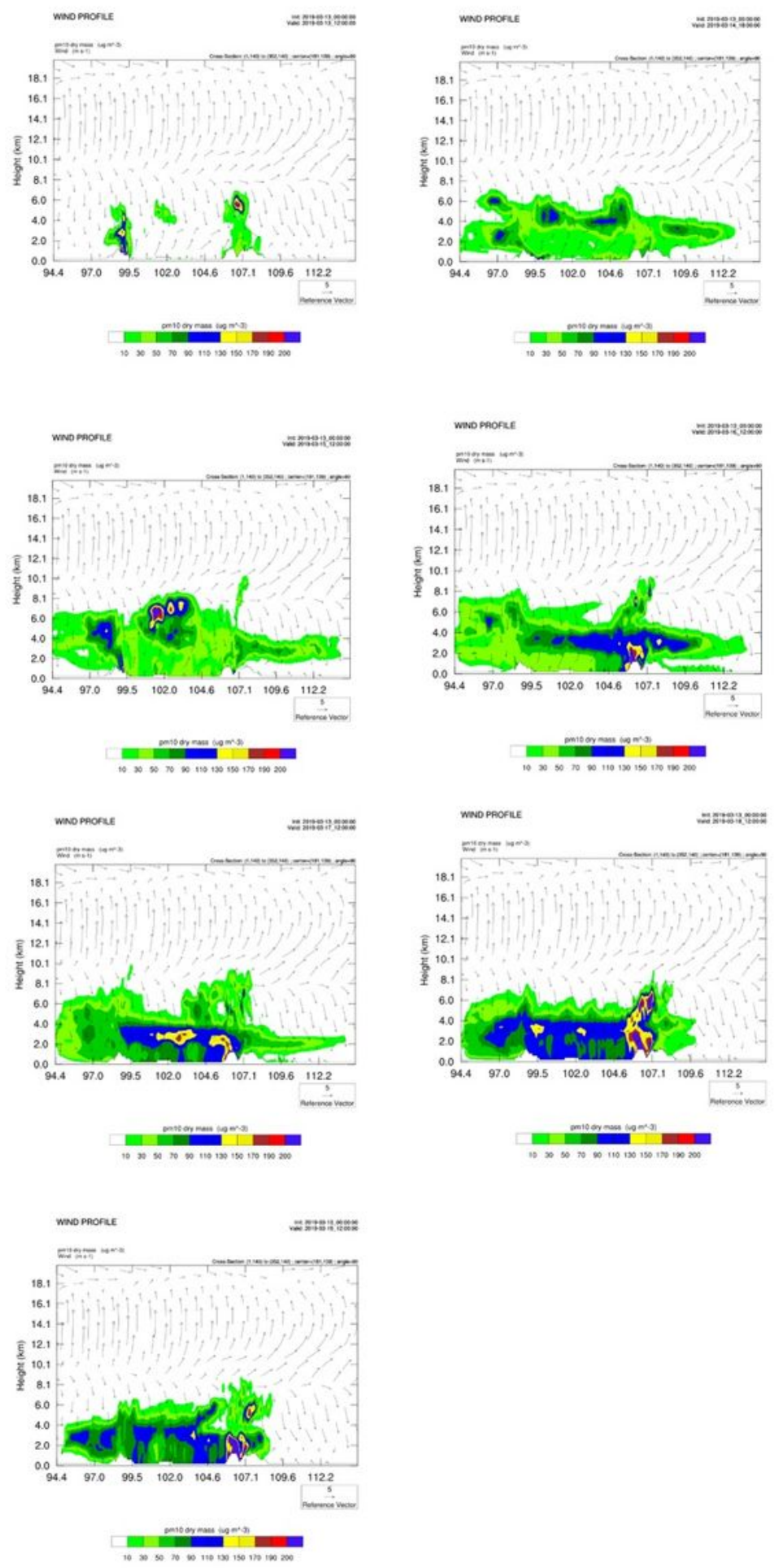

\section{Figure 16}

Predicted vertical profiles of wind and PM2.5 concentration along the path passing through Ubon Ratchathani on 13/3/2019 12:00, 14/3/2019 18:00, 15/3/2019 12:00, 16/3/2019 12:00. 17/3/2019 12:00 and 19/3/2019 12:00 UTC. The outline of the Central Highland in Vietnam can be seen up to $1.5 \mathrm{~km}$ high from 105.70 to 108.50 longitude at the bottom along the horizontal axes. And on the left is the 
outline of the Dawna mountain area in Khao Laem National Park near the border of Thailand and Myanmar. 